\title{
A Model Analysis of the Behavior of the Mediterranean Water in the North Atlantic
}

\author{
Yanli Jia, Andrew C. Coward, Beverly A. de Cuevas, and David J. Webb \\ National Oceanography Centre, Southampton, Southampton, United Kingdom
}

SYBREN S. DRIJFHOUT

Koninklijk Nederlands Meteorologisch Instituut, de Bilt, Netherlands

(Manuscript received 22 July 2005, in final form 20 June 2006)

\begin{abstract}
The behavior of the Mediterranean Water in the North Atlantic Ocean sector of a global ocean general circulation model is explored, starting from its entry point at the Strait of Gibraltar. The analysis focuses primarily on one experiment in which explicit watermass exchange between the Mediterranean Sea and the Atlantic at the Strait of Gibraltar is permitted. The model produces an exchange rate of approximately 1 $\mathrm{Sv}\left(\mathrm{Sv} \equiv 10^{6} \mathrm{~m}^{3} \mathrm{~s}^{-1}\right)$. This is comparable to estimates derived from field measurements. The density of the Mediterranean outflow, however, is lower than observed, mainly because of its high temperature (more than $2^{\circ} \mathrm{C}$ higher than in reality). The lower density of the outflow and the model's inadequate representation of the entrainment mixing in the outflow region cause the Mediterranean Water to settle in a depth range $\sim 800-1000 \mathrm{~m}$ in the North Atlantic, about $200 \mathrm{~m}$ shallower than observed. Here an interesting current system forms in response to the intrusion of the Mediterranean Water, involving three main pathways. In the first, the Mediterranean Water heads roughly westward across the basin and joins the deep western boundary current. In the second, the water travels northward along the eastern boundary reaching as far as Iceland, where it turns westward to participate in the deep circulation of the subpolar gyre. In the third, the water initially moves westward to the central Atlantic just north of $30^{\circ} \mathrm{N}$ before turning northwestward to reach an upwelling region at the Grand Banks off Newfoundland. At this location, the saline Mediterranean Water is drawn upward to the ocean upper layer and entrained into the North Atlantic Current system flowing to the northeastern basin; part of the current system enters the Nordic seas.
\end{abstract}

\section{Introduction}

The flux of the warm and saline Mediterranean Water (MW) into the North Atlantic Ocean through the Strait of Gibraltar, though small in magnitude [on the order of $1 \mathrm{~Sv}\left(\mathrm{~Sv} \equiv 10^{6} \mathrm{~m}^{3} \mathrm{~s}^{-1}\right)$; Bryden et al. 1994; Candela 2001], is one of several distinct water sources whose interactions determine the overall watermass distribution of the North Atlantic. Moreover, it is believed that the MW is also a saline source for the Nordic seas, which implicates its potential impact on the World Ocean circulation. At present, there are two hypotheses with regard to the route that the MW takes to arrive at the Nordic seas. Reid (1979) conjectured that the MW is transported northward in a deep $(>1000 \mathrm{~m})$ eastern

Corresponding author address: Dr. Yanli Jia, IPRC/SOEST, University of Hawaii, 1680 East West Road, POST Bldg. 401, Honolulu, HI 96822.

E-mail: yjia@hawaii.edu

DOI: $10.1175 / \mathrm{JPO} 3020.1$

(C) 2007 American Meteorological Society boundary undercurrent from the Gulf of Cadiz to the northern end of the Rockall Trough (near $60^{\circ} \mathrm{N}$ ), where it rises and flows over the Wyville-Thomson Ridge into the Nordic seas as part of the Atlantic inflow. This pathway of the MW has been termed the "deep source hypothesis" by McCartney and Mauritzen (2001) who also put forward an alternative "shallow source hypothesis." They proposed that the MW contributes to the saline characteristic of the North Atlantic Central Water (NACW) by blending with other water masses in the thermocline of the subtropical gyre. Thermocline waters are drawn upward into the North Atlantic Current (NAC) system, branches of which flow into the Nordic seas.

In the Nordic seas, the saline characteristic of the Atlantic inflow, including contributions from the MW either directly as in the deep source hypothesis or indirectly as in the shallow source hypothesis, combined with intense winter cooling increases the density of the surface water, which sets the condition for deep con- 
vective mixing and the formation of the North Atlantic Deep Water (NADW). The NADW flows southward in the deep western boundary current (DWBC) as the lower branch of the Atlantic overturning circulation. In this way, the MW (or its high salinity content) is thus recognized as an important ingredient of the Atlantic overturning circulation, and ultimately the global thermohaline circulation.

One support for the deep source hypothesis is a study by Iorga and Lozier (1999b) who estimated the velocity fields on two representative isopycnal surfaces of the Mediterranean Sea outflow with a diagnostic model that uses climatological hydrographic data in the North Atlantic and measurements of the water exchange through the Strait of Gibraltar. They showed continuous poleward flow along the eastern boundary on both surfaces carrying the MW all the way to $60^{\circ} \mathrm{N}$ where the model boundary lies. Beyond $60^{\circ} \mathrm{N}$, the likelihood of the MW rising and flowing over the Wyville-Thomson Ridge into the Nordic seas is deduced from the climatological pressure fields, which show the northward shoaling of the isopycnal surfaces to reach above the sill depth of the ridge.

One support for the shallow source hypothesis is a study by New et al. (2001) who analyzed three eddypermitting ocean circulation models of the North Atlantic that differ primarily in the discretization of the vertical coordinate. They showed that although the MW may reach as far north as $60^{\circ} \mathrm{N}$ in a deep eastern boundary undercurrent, none of the models allows the MW to rise and flow over the Wyville-Thomson Ridge into the Nordic seas. Instead, the saline Atlantic inflow is derived partly from water masses of western origin carried by the NAC and partly from the eastern North Atlantic water transported northward via a "shelf edge current" flowing around the continental margins in the upper ocean. The study does not discuss whether the MW contributes to the saline characteristic of the inflowing water masses in these models. However, Mauritzen et al. (2001) showed, through the analysis of observational data, laboratory experiments, and inverse modeling, how the MW may increase the salinity of the NACW in the eastern basin by an upward salinity flux in the Gulf of Cadiz. In this way, the MW is embedded in the inflowing water masses to the Nordic seas.

In this study, we provide a detailed description of the pathways of the MW in the North Atlantic starting from its entry point at the Strait of Gibraltar, as seen in an ocean general circulation model. Stepping ahead of the presentation, we find that the model solutions do not show evidence for the deep source hypothesis. Instead, we identify a location in the western North Atlantic where the MW upwells to the ocean upper layer and joins the NAC, part of which flows into the Nordic seas. This MW pathway is consistent with the shallow source hypothesis.

In what follows, we describe the model configuration and experimental design in section 2. Section 3 focuses on the watermass exchange at the Strait of Gibraltar and the influences from upstream in the western Mediterranean. The downstream evolution of the MW in the Gulf of Cadiz is examined in section 4, and the pathways of the MW in the North Atlantic basin are presented in section 5. The results are summarized in section 6 .

\section{Model description and experimental design}

The model used for this study is a fully global ocean model built within the U.K. Ocean Circulation and Climate Advanced Modeling (OCCAM) project. The numerics are based on the Bryan-Cox-Semtner (BCS) formulation (Bryan 1969; Semtner 1974; Cox 1984), which solves the ocean primitive equations using finite differences on a horizontal Arakawa-B grid (Arakawa 1966). The present implementation replaces the rigid lid of the BCS scheme with a free surface scheme similar to that described by Killworth et al. (1991), with modifications to increase computational efficiency. An improved advection scheme, known as the SplitQuadratic Upstream Interpolation for Convective Kinematics (QUICK) (Webb et al. 1998) with fourthorder accuracy, is used for both the tracer and velocity fields and in both horizontal and vertical directions. The model is configured to make use of multiprocessor computers for computational efficiency (Webb et al. 1997). Some details of the model relevant to the present study are described below.

The model attains its global coverage by using two horizontal grids (Coward et al. 1994): a rotated grid for the North Atlantic, the Mediterranean, and the Arctic and a conventional latitude-longitude grid for the rest of the world oceans. The two grids match exactly at the geographical equator in the Atlantic. In the regions of interest for this study, the Mediterranean and the North Atlantic that are connected at the Strait of Gibraltar and lie within the rotated grid, the model latitude and longitude lines run approximately from south to north and from east to west. The grid resolution is $0.25^{\circ}$ in both directions. The model has 36 vertical levels, with grid space ranging from $20 \mathrm{~m}$ near the ocean surface to $250 \mathrm{~m}$ at depth. The model bathymetry is based on the Digital Bathymetry Data Base 5-minute (DBDB5) by the U.S. Naval Oceanographic Office, with modifications to important sills and straits (including the Strait of Gibraltar).

The model uses Laplacian diffusion and viscosity to 
represent horizontal mixing. Tracer diffusion coefficient is set to $100 \mathrm{~m}^{2} \mathrm{~s}^{-1}$, and viscosity for momentum is $200 \mathrm{~m}^{2} \mathrm{~s}^{-1}$. Vertical momentum mixing is also in Laplacian form with a coefficient of $1 \mathrm{~cm}^{2} \mathrm{~s}^{-1}$. The Richardson-number-dependent vertical mixing is applied to the tracer fields with a background diffusivity of $0.5 \mathrm{~cm}^{2} \mathrm{~s}^{-1}$.

The model ocean was initially at rest but assigned with potential temperature and salinity taken from the Levitus (1982) annual mean fields. The model was forced at the ocean surface by wind stress from a 198688 European Centre for Medium-Range Weather Forecasts (ECMWF) monthly climatology (Siefridt 1994), and heat and freshwater fluxes calculated in such a manner that they are equivalent to a surface temperature relaxation toward the monthly climatology of Levitus and Boyer (1994) and a surface salinity relaxation toward Levitus et al. (1994) on a time scale of 30 days.

To minimize drift from the initial state below the surface level, the model's potential temperature was restored toward the annual mean climatology of Levitus and Boyer (1994), and salinity toward that of Levitus et al. (1994) on a time scale of 360 days. This restoring was turned off at the end of year 4. Immediately following, the model's kinetic energy increases sharply but becomes steady from year 8 (not shown here). Thus, the model state at the end of year 8 was used as a starting point for sensitivity experiments in various studies, such as Saunders et al. (1999), Webb (2000), Lee et al. (2002), and Drijfhout et al. (2003). The main model experiment has an integration length of $25 \mathrm{yr}$ in total. Such an integration time, though short relative to the thermohaline-adjustment time scale of the deep ocean to atmospheric conditions, does allow the velocity field to reach a dynamical quasi-equilibrium state as demonstrated by previous modeling studies of the North Atlantic circulation (Döscher et al. 1994; Gerdes and Köberle 1995).

To assist with the understanding of the behavior of the MW in the main experiment, we performed one additional sensitivity experiment, which has the same setup as the main experiment except that the Strait of Gibraltar is closed; that is, no exchange is allowed between the Atlantic and the Mediterranean. The integration starts from the state at the end of year 8 and matches the length of the main experiment thereafter. This experiment may be viewed as a spindown exercise from which we observe the oceanic response to the withdrawal of the MW forcing at the eastern boundary. The solution from this closed-strait experiment will be contrasted to that from the open-strait experiment (the main experiment) to demonstrate the effects of the
MW overflow process on the circulation in the North Atlantic.

It is worth pointing out here that the representation of dense overflows (e.g., Nordic seas overflows, Mediterranean overflow) in ocean general circulation models is difficult because of the complex nature of the problem. First, the geographic character of straits (usually narrow with shallow sills over which dense water must flow) creates severe physical constraints. The Strait of Gibraltar is about $15 \mathrm{~km}$ at the narrowest section (known as the Tarifa Narrows, or the narrows) and is less than $300 \mathrm{~m}$ at the shallowest sill (Camarinal Sill, or the sill, which is to the west of the narrows). Thus, ocean circulation models that can be used to perform long integrations at present do not have the horizontal resolution necessary to adequately resolve the strait. If the strait is included in such a model configuration, its width is usually much exaggerated, and the dynamics of flow exchange (e.g., hydraulic control) is lost. Second, the observed characteristics of the entrainment mixing associated with the downslope evolution of dense overflow are difficult to prescribe precisely because of the lack of control that we have on the mixing processes in ocean models (convective mixing, implicit diapycnal mixing associated with advection schemes, etc.). Excessive mixing will result in the overflow water rapidly losing its dense characteristic and becoming neutrally buoyant at a too-shallow depth. On the other hand, insufficient mixing tends to preserve the dense characteristic of overflow water too well and results in dense water staying close to the bathymetry well beyond the overflow region. The Dynamics of North Atlantic Models (DYNAMO) project (Willebrand et al. 2001) presents examples of both cases for the northern overflows in three models that differ mainly in the discretization of the vertical coordinate, namely, geopotential levels, isopycnal layers, and terrain-following (sigma) coordinates. It is found that there is excessive mixing in the level and sigma models and insufficient mixing in the isopycnal model.

Because of these difficulties, the Mediterranean overflow process is often side stepped in basin-scale or global-scale ocean general circulation models by closing the Strait of Gibraltar and employing an artificial boundary condition. Usually, a restoring condition of temperature and salinity (or the density profiles) toward climatology is applied in the Gulf of Cadiz in an attempt to capture the MW characteristics (e.g., New et al. 2001). Previous modeling experiences show that such a treatment is inadequate in generating the current system necessary to transport sufficient saline MW away from the Gulf of Cadiz for the establishment of a realistic salt tongue (Spall 1990; Gerdes et al. 1999). 


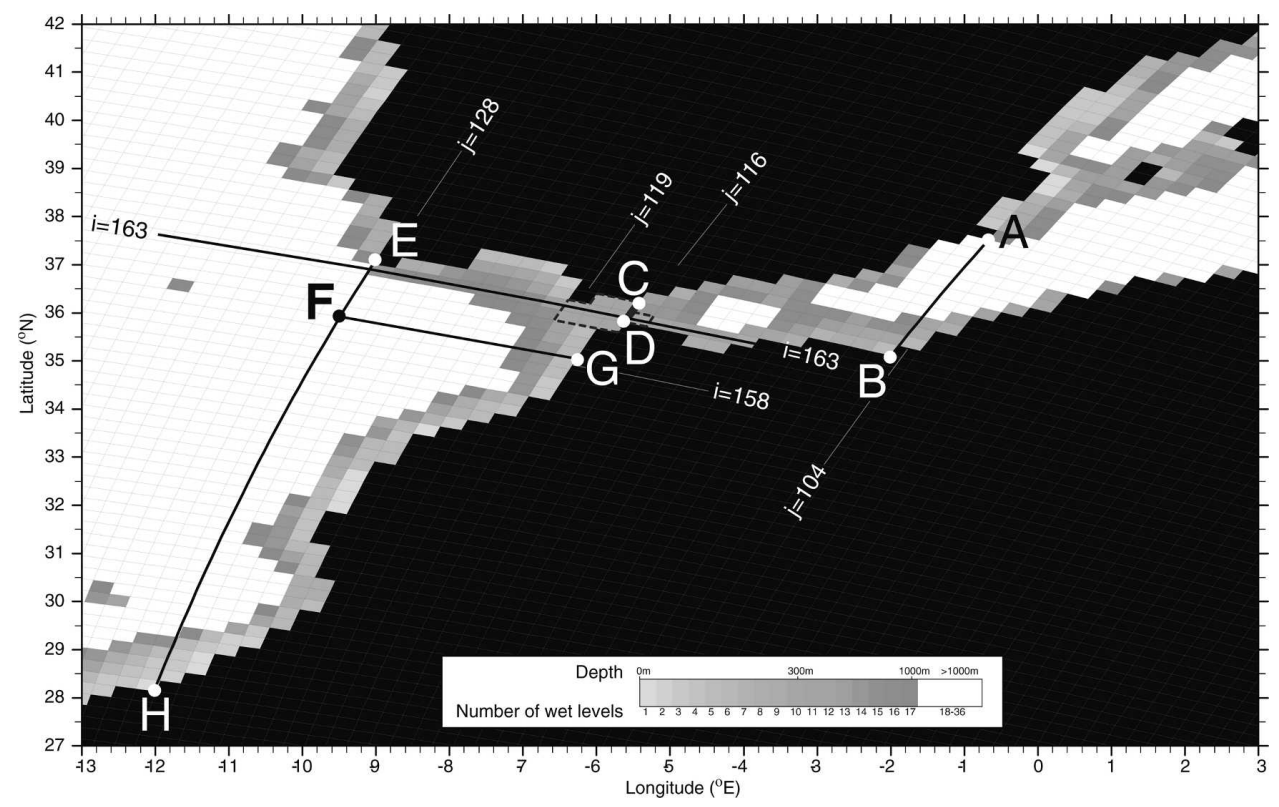

FIG. 1. Model grid layout in the region of the Strait of Gibraltar; every grid line is drawn. Section C-D is the model strait where the MW properties and exchange flux are computed. All other locations are discussed in sections 3 and 4 of the main text.

Another reason for the lack of salt flux is that the prescribed fields, usually climatological, do not contain enough of the high salinity characteristic of the MW. The result is a poor representation of the MW in the whole of the North Atlantic.

The model used for this study includes an open Strait of Gibraltar in the main experiment to explicitly allow the MW to enter the Atlantic. The watermass exchange at the strait and the mixing process in the overflow region are examined in great detail and compared with observations. Although the present model does not resolve the width of the strait or represent the mixing process in a realistic manner (as will be seen later), the analysis has its value in providing an overview of the MW overflow process that one might expect from models with similar configurations.

\section{Exchange at the Strait of Gibraltar}

Bryden et al. (1994), using measurements from the Gibraltar Experiment conducted in 1985 and 1986, estimated the time-averaged exchange to be $0.72 \mathrm{~Sv}$ for the Atlantic inflow and $0.68 \mathrm{~Sv}$ for the Mediterranean outflow. The larger inflow ensures that the net salt exchange is zero at the strait. The excess $(0.04 \mathrm{~Sv})$ is also necessary to balance the net loss of water at the sea surface through evaporation within the Mediterranean. Higher mean exchange rates of 1.01/0.97 Sv were reported by Candela (2001) from a 2-yr-long currentmeter time series (1994-96). It is unclear whether the different estimates of the mean exchange given by Bryden et al. (1994) and Candela (2001) are due to interannual variability or the methods used.

The representation of the Strait of Gibraltar in the main experiment is shown in Fig. 1. Temperature and salinity are defined in the center of each model grid box, and velocities are defined at the corners of these boxes. This is the Arakawa-B grid (Arakawa 1966). The velocities situated at land points are set to zero values (no-slip boundary condition). The area enclosed within the thick dashed line is the model Strait of Gibraltar and has a constant depth of $324 \mathrm{~m}$ (10 model levels). For computing the transport of the exchange through the strait, we take the narrowest section from $\mathrm{C}$ to $\mathrm{D}$, as indicated. It is $50 \mathrm{~km}$ (two grid intervals) wide, and the nonzero velocity point in the middle of the section is located at $36.1^{\circ} \mathrm{N}, 5.3^{\circ} \mathrm{W}$. In the grid layout shown, two grid intervals are the minimum necessary to allow flow through a gap. It is clear that the model strait is not only wider than it is in reality, but also assumes a channel geometry instead of a sill, limited by the resolution. In the closed-strait experiment, the three grid cells to the west of section C-D are filled to become land, which blocks the communication between the North Atlantic and the Mediterranean.

Shown in Figs. $2 \mathrm{a}-\mathrm{c}$ are the property profiles at the model strait (section C-D in Fig. 1). The solid line is the average over the last five years of the model integration (taken here as the "final" state), and the dashed line is 


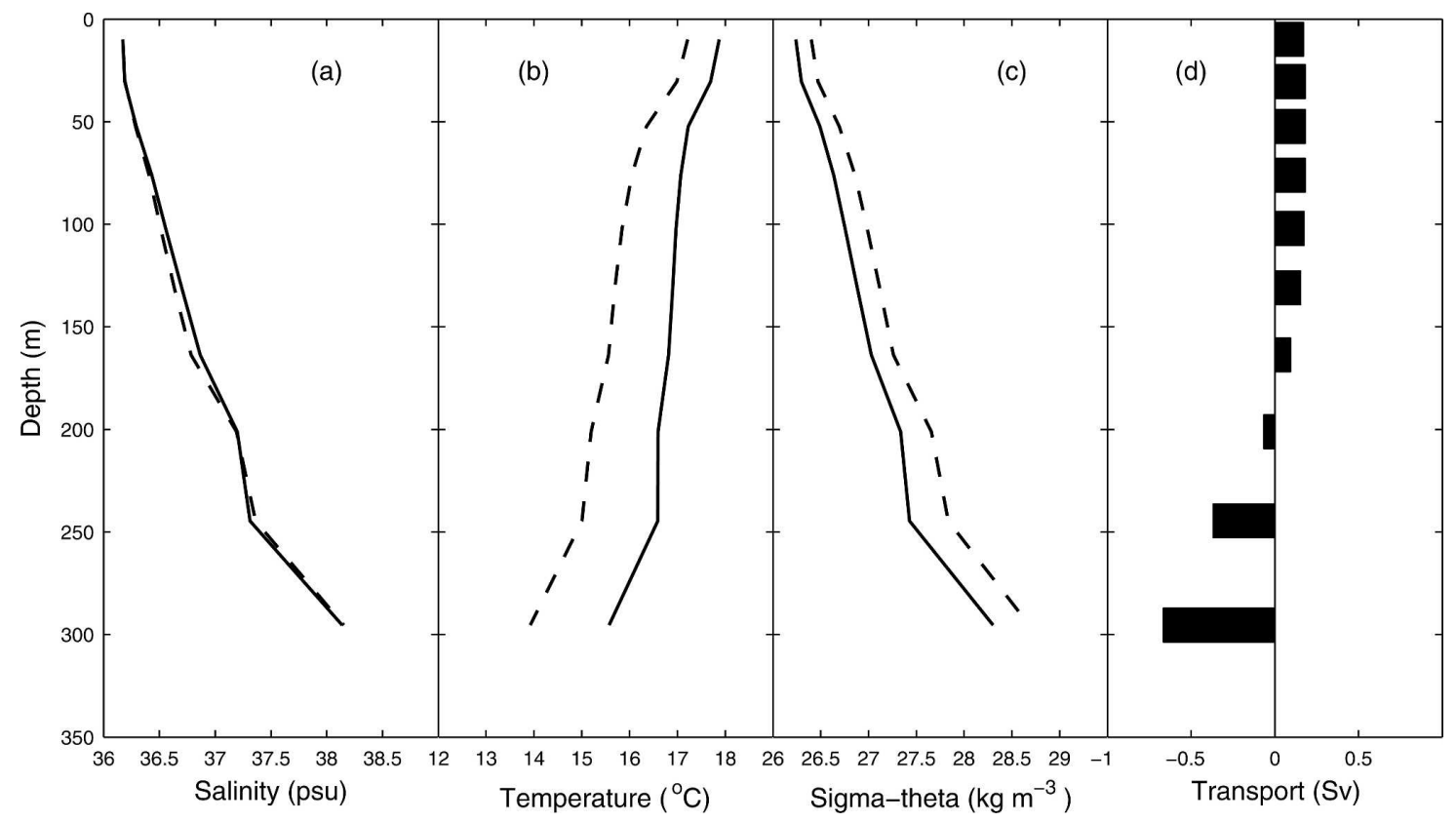

FIG. 2. Section mean profiles at the model Strait of Gibraltar of (a) salinity, (b) potential temperature, and (c) potential density anomaly: 5-yr mean (solid lines) and model "initial state" (dashed lines). (d) The 5-yr mean transport at the model strait; the bars are plotted at the depths of the model levels.

the annual mean from year 8 of the integration (taken here as the "initial" state). Figure $2 \mathrm{~d}$ displays the 5-yr mean transport across the strait, which shows that the Atlantic water flows into the Mediterranean above 180 $\mathrm{m}$ (approximately) and the MW flows out with intensification at the sill depth. The profiles show the gradual transition in properties over a considerable depth range around the interface, indicating significant mixing between the Atlantic inflow and the Mediterranean outflow.
There is little change from year 8 to the final state in salinity (Fig. 2a). There is, however, a significant increase in potential temperature throughout the whole water column. In particular, the temperature of the outflowing MW exceeds $15^{\circ} \mathrm{C}$ in the 5 -yr mean (Fig. 2b). Figure 3 shows the time evolution of the transportweighted potential temperature and salinity of the MW at the model strait (sum of the bottom three levels). The drift in temperature is most severe from year 8 to 18 , and the rate of increase is much slower in the later
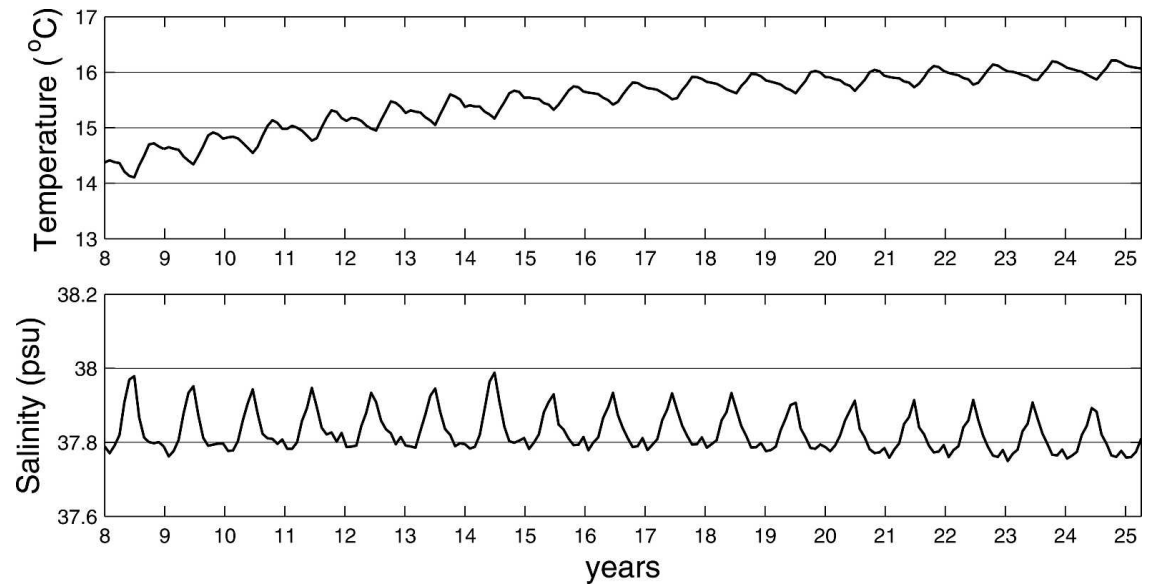

FIG. 3. Time variations of the transport-weighted (top) temperature and (bottom) salinity of the MW (westward flow) at the model Strait of Gibraltar. 


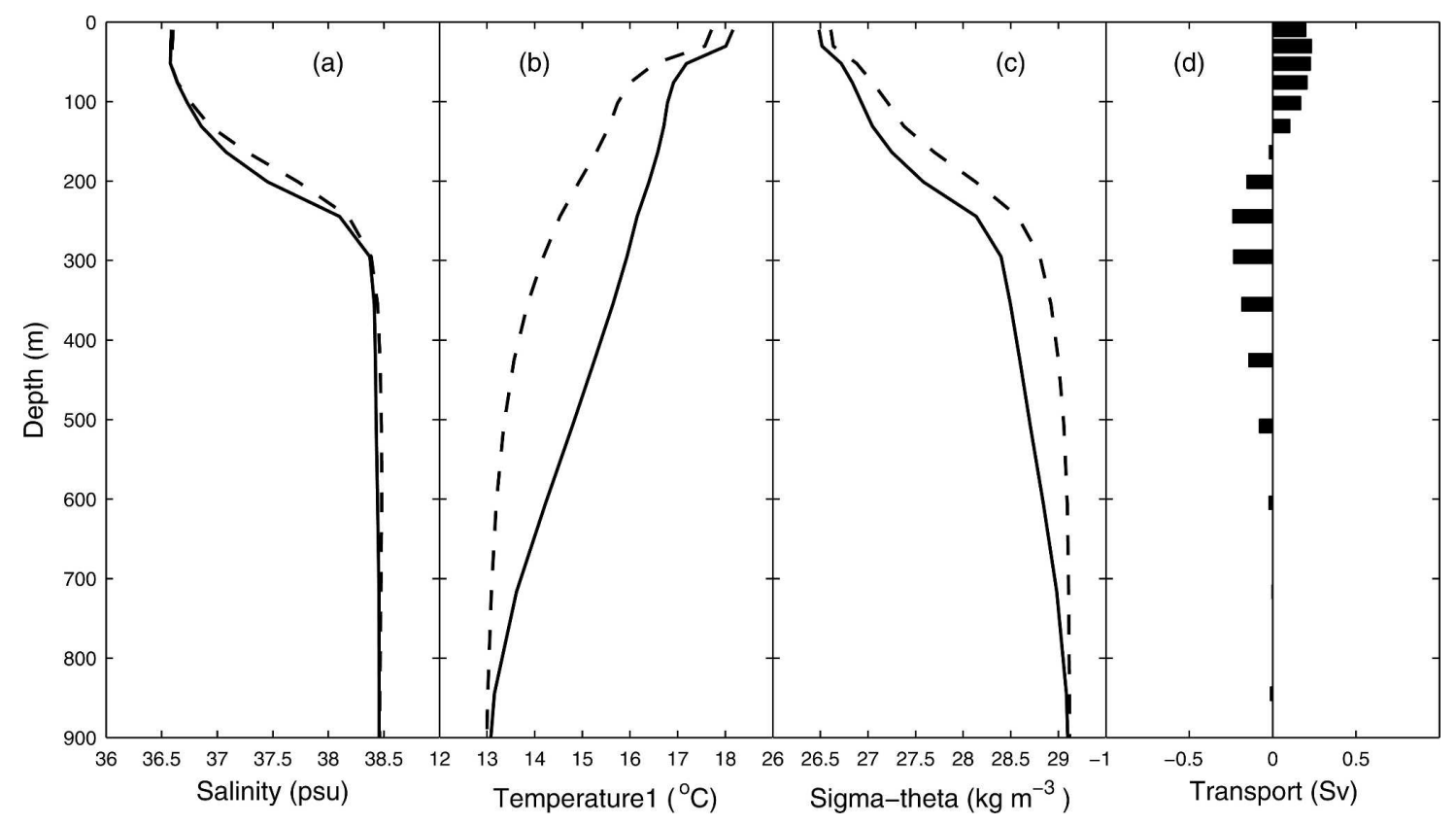

FIG. 4. As in Fig. 2 but for section A-B (see Fig. 1) in the western Mediterranean.

years. There is also a hint of freshening toward the end of the integration. Higher potential temperature means less dense MW at the strait $\left(27.4<\sigma_{\theta}<28.3\right.$ below 180 m; Fig. 2c). Baringer and Price (1997a, their Fig. 14) showed that the density range for the MW at the western end of the strait is between 28.0 and $28.9 \sigma_{\theta}$ with the transport mostly in the highest density.

Examination of the conditions in the western Mediterranean suggests that the drift comes from upstream. Shown in Fig. 4 are the mean properties along a section at the entrance to the Alboran Sea in the western Mediterranean (section A-B in Fig. 1). While the salinity remains close to the initial state, the potential temperature has increased dramatically above $900 \mathrm{~m}$. Transport analysis (method explained in section 4b) confirms that the MW exiting the Strait of Gibraltar is drawn from the Alboran Sea, mostly in the depth range 180-500 m (Fig. 4d) where the temperature is approximately $15^{\circ}$ $17^{\circ} \mathrm{C}$ and salinity is between 37.7 and 38.4 practical salinity units (psu).

In reality, the characteristics of the MW exiting through the Strait of Gibraltar are primarily those of Levantine Intermediate Water (LIW) formed in the northern Levantine Basin in the eastern Mediterranean through winter convection (Wüst 1961; Bryden and Stommel 1982; Gascard and Richez 1985; Parrilla et al. 1986). LIW enters the western Mediterranean through the Strait of Sicily and can be traced almost everywhere in the basin in the depth range $200-600 \mathrm{~m}$. It has a typical potential temperature near $13^{\circ} \mathrm{C}$ and salinity slightly greater than $38.4 \mathrm{psu}$. In the model, the origin of the MW outflow is also in the eastern Mediterranean. Its high temperature reflects a severe imbalance between the sea state and the atmospheric forcing in the formation region.

The transports of the Atlantic inflow and Mediterranean outflow at the model strait are steady from year 8 to the end of the integration. The average transports for the last 5 years are 1.13 and $1.09 \mathrm{~Sv}$, respectively, yielding a net inflow of $0.04 \mathrm{~Sv}$. These values compare favorably with estimates from recent measurements. This gives us the incentive to investigate the behavior of the MW farther downstream, bearing in mind that the high potential temperature of the MW at the strait will undoubtedly limit the extent of its vertical penetration in the Atlantic.

\section{Mixing and circulation in the Gulf of Cadiz}

\section{a. Mixing}

Baringer and Price (1997a,b), through the analysis of measurements collected during the Gulf of Cadiz expedition, studied the dynamics of the Mediterranean outflow and provided a detailed description of the evolution of the outflow in the Gulf of Cadiz. Following the idea of Smith (1975), they showed that the combination of bottom stress and entrainment stress determines the behavior of the outflow. Bottom stress is necessary to overcome the geostrophic constraint and allow the dense flow to descend down the continental slope in- 


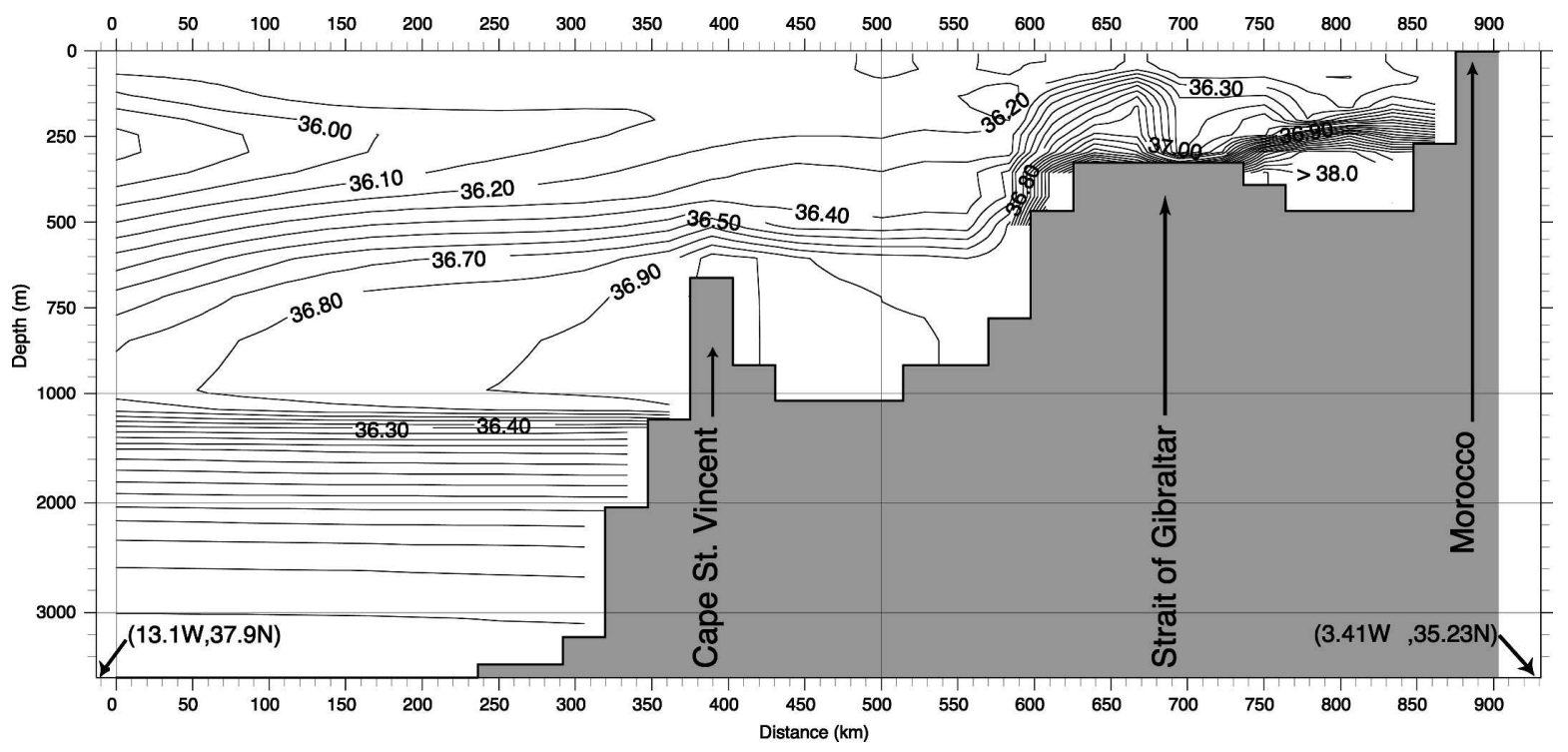

FIG. 5. Salinity along a model longitude $(i=163$ in Fig. 1) from the Alboran Sea through the Strait of Gibraltar to Cape St. Vincent and out to the open Atlantic.

stead of following $f / h$ contours, whereas entrainment erodes the density anomaly of the outflow, thus limiting its vertical penetration and causing it to become neutrally buoyant before reaching the bottom of the ocean. They also discovered that the downstream evolution of the MW is characterized by intense localized entrainment mixing during the initial descent of the continental slope. Consequently the transport of the mixed MW doubles from $0.7 \mathrm{~Sv}$ at the western end of the strait over a distance of less than $100 \mathrm{~km}$ downstream by entraining the overlying fresher and lighter NACW. In the meantime, the maximum salinity undergoes rapid reduction. By the time it reaches Cape St. Vincent the outflow is neutrally buoyant at a core depth of about $1000 \mathrm{~m}$ and the maximum salinity is around $36.6 \mathrm{psu}$.

The OCCAM ocean model includes a bottom stress in the form of a quadratic drag law. However, the drag coefficient is set to $1 \times 10^{-3}$, which is smaller than 2-12 $\left(\times 10^{-3}\right)$ as estimated by Baringer and Price (1997b). The entrainment stress is not explicitly parameterized. Instead, the model allows convective adjustment whenever there is heavier water overlying lighter water, which instantly homogenizes water properties of the affected region vertically. The application of tracer diffusion in the horizontal and vertical directions in the model will result in strong implicit diapynal mixing in regions of steeply sloping isopycnals. We expect both the convective adjustment and the implicit diapycnal mixing to contribute to the erosion of the density of the Mediterranean outflow in the present model simulation.

Shown in Fig. 5 is salinity along a model longitude $(i=163$ in Fig. 1) from the Alboran Sea (right) through the strait to Cape St. Vincent and out to the open Atlantic (left) in the main experiment. This section approximates the westward pathway of the MW in the Gulf of Cadiz. At the model strait, the most saline water ( $238.1 \mathrm{psu})$ is found at the deepest model level as already seen in Fig. 2a. The initial descent of the MW is a jump of $141 \mathrm{~m}$ (from model levels 10 to 12). It seems that the saline water simply drops down the step with little mixing. Closer inspection reveals that uniform properties (indication of convective adjustment) are present for levels 10 and 11 with much reduced salinity (37.7 psu), but level 12 (the bottom level) has an unexpected high salinity (38.2 psu). This is caused by an overshoot associated with the advection scheme that is fourth order in accuracy in the interior but reduces to second order near bathymetry or land. Numerical undershoot is also present in the neighboring grid points. The saline water experiences greater dilution in the next step down to $779 \mathrm{~m}$ (model level 15). Here the water properties are not vertically uniform; thus it is most likely that lateral mixing (or implicit diapycnal mixing) is at work. Farther downstream in the Gulf of Cadiz, there is a gradual descent to a maximum depth $1068 \mathrm{~m}$ (bottom of level 17), while the salinity reduces to around 36.9 psu near Cape St. Vincent, which is about 0.3 psu higher than observed at this location. Figure 6 shows the time evolution of the salinity profile averaged along section E-F near Cape St. Vincent (see Fig. 1). The increase in salinity and the upward migration of the MW core are visible in the first 10 years of the time series. Salinity is steady in the last 5 years with 


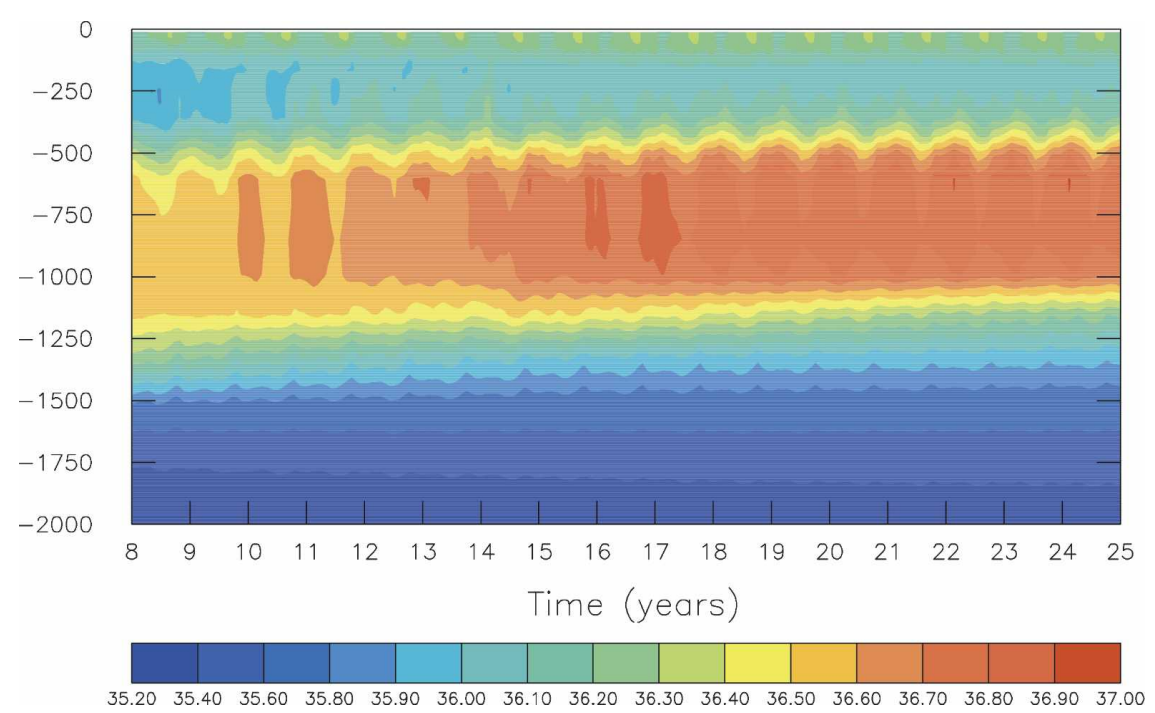

FIG. 6. Time evolution of the salinity profile averaged along section E-F (see Fig. 1) in the western Gulf of Cadiz.

the maximum on model levels 16 and 17 (depth range $779-1068 \mathrm{~m}$ ). This is about $200 \mathrm{~m}$ shallower than observed.

To quantify entrainment, we show in Fig. 7 the transport streamfunction on a zonal-vertical plane from (left) Cape St. Vincent (section E-H; see Fig. 1) through the strait (section C-D) to (right) the Alboran Sea (section A-B). The vertical coordinate is in potential density anomaly $\left(\sigma_{\theta}\right)$ so that the change in the outflow density may be seen clearly. The horizontal coordinate is in model grid $(j)$ index.

In the Alboran Sea (the region with the $j$ index 115 and lower), the westward-flowing MW has a transport near $0.75 \mathrm{~Sv}$, most of which $(\sim 0.50 \mathrm{~Sv})$ has a potential density anomaly near 28.4. At the model strait $(j=$ 116-119), some mixing of the inflow and outflow takes place, which is noted by the upward movements of the $0.50-\mathrm{Sv}$ and $0.75-\mathrm{Sv}$ contours of the MW and the downward movement of the 1.0-Sv contour of the NACW. From $j=119$ to $j=120$, the transport streamlines for the westward flow (the MW) take a downward dive; this is the location where the MW takes the first step down and a severe numerical overshoot occurs. In the next step (from $j=120$ to $j=121$ ), the lower part of the NACW $\left(\sigma_{\theta} \geq 26.4\right)$ is entrained into the MW, the density of which experiences a great reduction to about 27.4, consistent with the salinity decrease shown in Fig. 5 . The volume of the mixed MW increases to a maximum transport of $2.0 \mathrm{~Sv}$. There is very little variation in property or transport westward from there.

In terms of the doubling of the MW transport and the intense localized mixing at the initial descent down the continental slope, the model results compare well with the analysis by Baringer and Price (1997a). This may have happened by coincidence rather than design. Previous modeling studies with the Denmark Strait overflow (e.g., Roberts et al. 1996; Willebrand et al. 2001) have shown that a model of this type (with geopotential levels as the vertical coordinate) tends to produce strong mixing through either convective adjustment or implicit diapycnal diffusion in such a situation, which prevents the dense overflow from reaching a realistic depth. The fact that there is intense localized mixing of the MW in nature may have made this model deficiency less damaging. Nevertheless, the convective adjustment and implicit diapycnal diffusion, which are the model's representation of the entrainment stress, do make the MW mix rather uniformly; thus there is a lack of the dense variety in the mixed MW. For example, after intense mixing down the initial steps, the model MW density is around 27.4, whereas the observed density range is from 27.3 to $28.0\left(\sigma_{\theta}\right)$ with the transport fairly evenly distributed over the range (Baringer and Price 1997a). This must have contributed to the insufficient vertical penetration of the MW in the model.

The model's numerical overshoot problem may be of some concern. Its occurrence is not unexpected when a second-order advection scheme is used in places where extreme values exist (as in the Strait of Gibraltar). There is a possibility that the dense bottom level created by the overshoot in the initial descent may have caused the model MW to descend farther than it would have, which is desirable, though by means of a numerical error. We intend to resolve this problem by conducting further experiments using different advection schemes in a future study. 


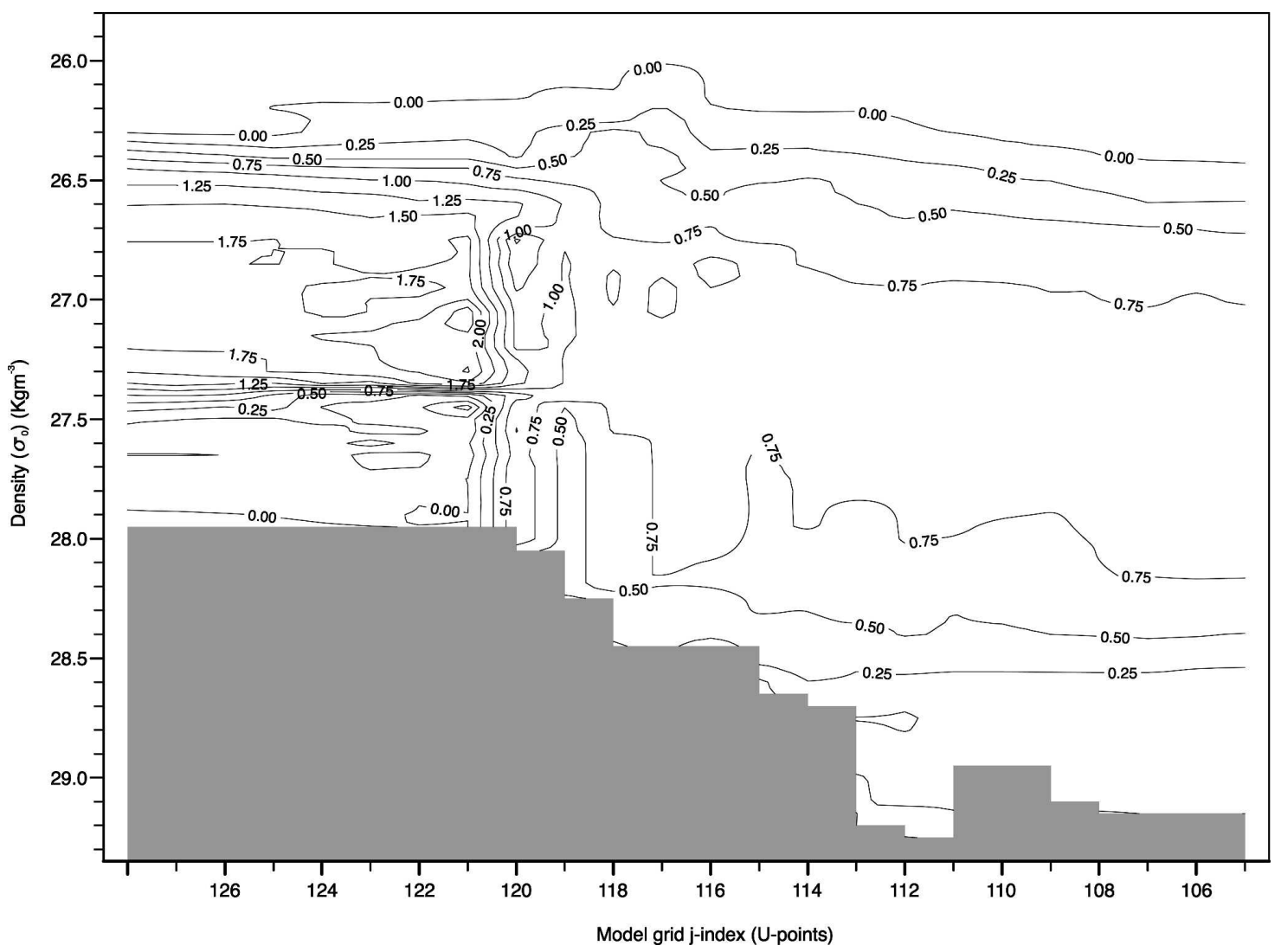

FIG. 7. Transport streamfunction (Sv) plotted in the zonal (in model $j$ index) and vertical (in $\sigma_{\theta}$ ) plan in the Gulf of Cadiz.

\section{b. Circulation}

To examine the circulation in the Gulf of Cadiz we first use an integrated quantity, the vertical transport through an area bounded by zonal and meridional sections, defined as

$$
w_{\operatorname{tran}}(z)=\sum_{N}\left(\int_{\mathrm{zb}}^{z} \int_{\mathrm{ls}}^{\mathrm{le}} v d l d z\right),
$$

where $v$ is the horizontal velocity across a section (a zonal or meridional section on the model grid) bounded by ls and le, zb is the bottom depth of the ocean, and $N$ is the total number of (zonal and meridional) sections bounding the area. The velocity $v$ is positive into the enclosed region, and then $w_{\text {tran }}(z)$ represents the sum of net horizontal transport into the region below the depth $z$; thus positive $w_{\text {tran }}(z)$ indicates upwelling at depth $z$.

In section $3, w_{\text {tran }}(z)$ computed for the Alboran Sea, bounded by two sections (A-B and C-D in Fig. 1), was used to determine the depth range of the source water exiting the Strait of Gibraltar in the main experiment.

For the northern Gulf of Cadiz bounded by three sections $(\mathrm{C}-\mathrm{D}, \mathrm{E}-\mathrm{F}$, and $\mathrm{F}-\mathrm{G}$ in Fig. 1$), w_{\text {tran }}(z)$ is shown in Fig. 8 for the main experiment (continuous line). Several observations can be made. First, there is a very weak vertical transfer $\left[w_{\text {tran }}(z)=-0.07 \mathrm{~Sv}\right]$ at depth $222 \mathrm{~m}$ (base of model level 8). Typical circulation in the Gulf of Cadiz above this depth is cyclonic with a strong eastward component to feed the leakage to the Mediterranean (Fig. 9a), which is little affected by the dense MW below. Second, below the ocean upper layer, there is downwelling [negative $w_{\text {tran }}(z)$ ] that increases with depth, reaching a maximum $\left[w_{\text {tran }}(z)=\right.$ $-1.66 \mathrm{~Sv}]$ at $465 \mathrm{~m}$ (base of model level 12). In this depth range, the inflowing MW sinks while entraining water from the south (across section F-G), leaving a cyclonic circulation in the Gulf of Cadiz. Below the maximum at $465 \mathrm{~m}$ and above $659 \mathrm{~m}$ (base of model level 14), the MW continues to entrain water from the south, attaining a maximum transport of about $2 \mathrm{~Sv}$ of mixed MW, more than half of which sinks and the rest (the upper MW) leaves the Gulf of Cadiz across section E-F. Third, the vertical exchange across depth $915 \mathrm{~m}$ (base of model level 16) is weak [ $\left.w_{\text {tran }}(z)=0.05 \mathrm{~Sv}\right]$. In the depth range 659-915 m, the downwelled mixed MW is carried westward away from the Gulf of Cadiz across 


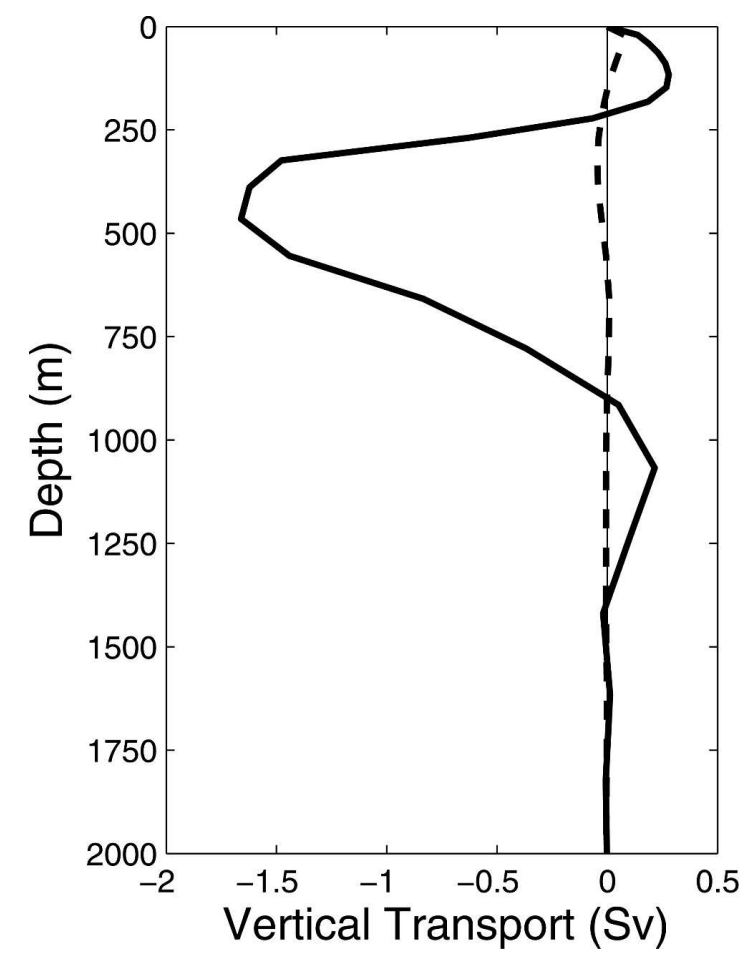

FIG. 8. Mean vertical transport $w_{\text {tran }}(z)$, as defined in the main text, for the northern Gulf of Cadiz: open-strait experiment (solid curve) and closed-strait experiment (dashed curve).

section E-F (Fig. 9b). West of the Gulf of Cadiz, some of the MW flows northward along the Portuguese coast, some continues westward, and the rest takes a cyclonic turn back to the eastern boundary to flow southward along the African continental shelf, which then leaves the coast to flow westward in the latitudinal range between $30^{\circ}$ and $32^{\circ} \mathrm{N}$.

In Fig. $8, w_{\text {tran }}(z)$ is also shown for the closed-strait experiment (dashed line). It is apparent that without the intrusion of the MW, the circulation in the northern Gulf of Cadiz is almost nondivergent (very weak vertical velocity) at all depths. There is, however, a cyclonic circulation in the upper ocean around the Gulf of Cadiz (Fig. 9c) except that the flow into the gulf is much weaker than in the main experiment (Fig. 9a). The strong flow is necessary in the main experiment to feed the leakage to the Mediterranean, and this extra transport comes from the west in the form of the Azores Current. Below the surface layer (222-465 m), the sinking of the MW in the main experiment enhances the transport of the Azores Current west of the Gulf of Cadiz. The presence of the Azores Current is consistent with the mechanism proposed by Jia (2000) and supported by Özgökmen et al. (2001) based on the $\beta$-plume theory, which says that dipole circulation forms when there is a downward mass transfer across a density sur- face (Stommel et al. 1958; Luyten and Stommel 1986; Pedlosky 1996), with a cyclonic circulation in the upper layer and anticyclonic circulation in the lower layer.

At the MW depth, the flow field in the closed-strait experiment is weak (Fig. 9d), an indication that it is not influenced by direct external forcing. However, the intrusion of the MW in the open-strait experiment has induced a significant flow system in the Gulf of Cadiz (Fig. 9b). If $\beta$-plume theory applies here, anticyclonic circulation is expected. Instead, cyclonic circulation still prevails in the Gulf of Cadiz. A cyclonic circulation of the MW at this location is deduced from a climatological database by Iorga and Lozier (1999a). Daniault et al. (1994) also found a cyclonic circulation in this region from direct observations. Clearly there are additional dynamics at work here in addition to the $\beta$-plume theory.

\section{Pathways of the Mediterranean Water in the North Atlantic}

\section{a. Salinity distribution and the flow field}

The North Atlantic climatology compiled by Lozier et al. (1995) shows a distinct warm and saline interior in the North Atlantic basin referred to as the Mediterranean tongue, extending northward along the eastern boundary, westward all the way to the western boundary, and vertically over several hundred meters. There have been many studies of the dynamics of the Mediterranean salt tongue, from treating salt as a passive tracer whose distribution is maintained by a prescribed balance of advection and diffusion to considering that the MW plays an active role in producing the characteristics of the flow field that spreads it. The modeling study of Stephens and Marshall (1999) is an example of the former. They suggest that wind forcing defines the potential vorticity field at the depth of the Mediterranean salt tongue and sets up the pathways for the spreading of the MW. On the other hand, Spall (1999), using a simple idealized model, shows that the largescale spatial variations in the strength of salt fingering (parameterized as a diapycnal mass flux) determine the circulation and therefore the shape of the Mediterranean salt tongue. In Spall's study, salt fingering is the active part played by the MW. In both of these studies, the effects of meddies (parameterized as a distributed mass source in the basin interior) are also considered and shown to shift the salt tongue southward or extend its spatial scale westward. Enhanced lateral mixing due to mesoscale eddies has also been proposed as an effective spreading mechanism (Spall et al. 1993). For more information on previous studies of the Mediter- 
(a)
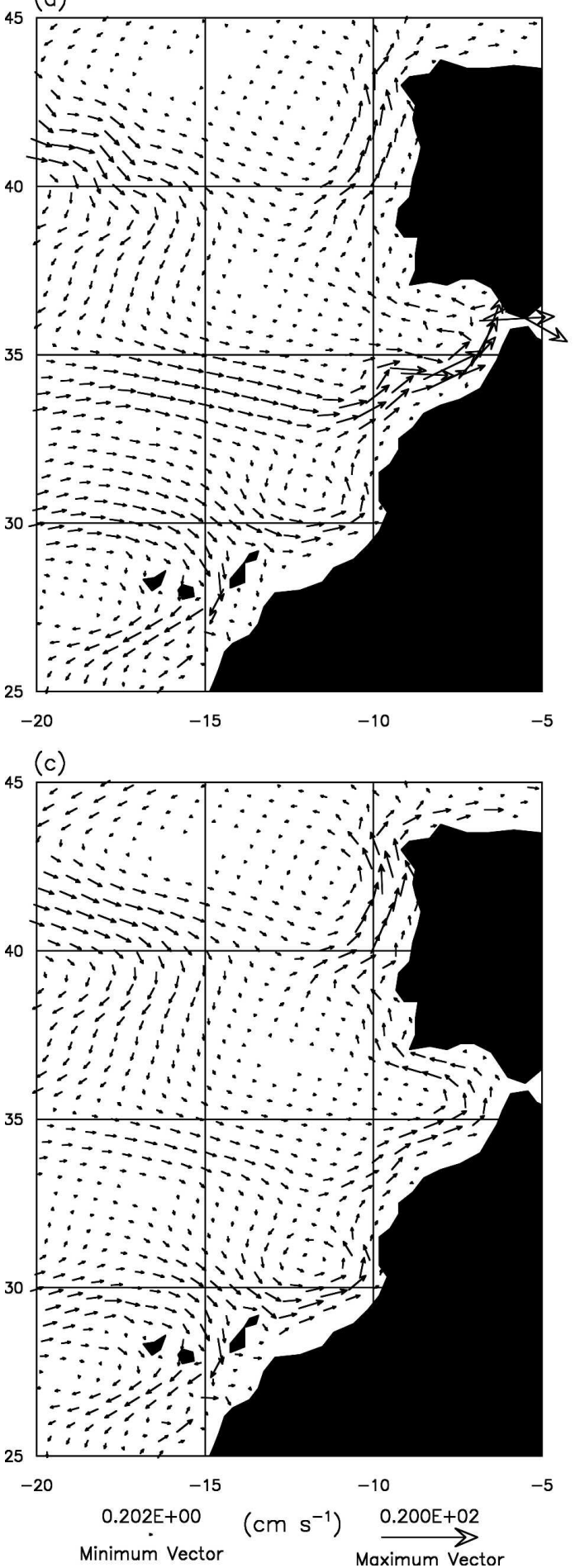

(b)
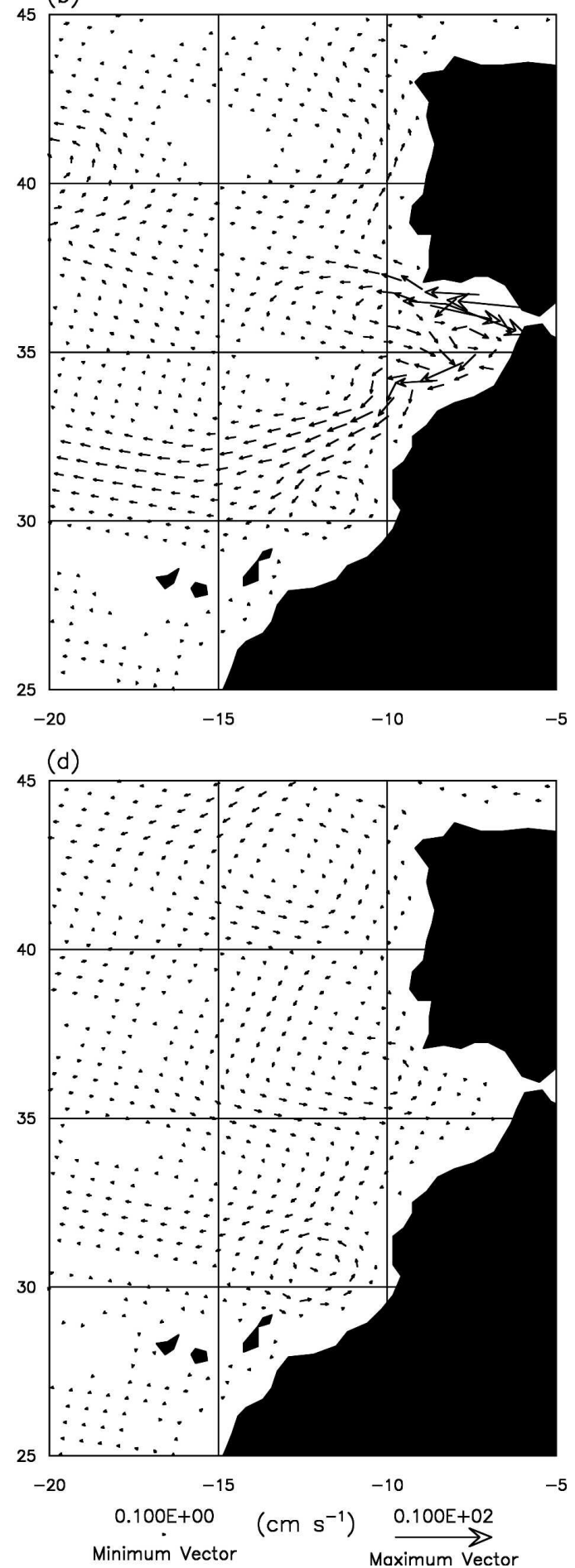

FIG. 9. Velocity field in the Mediterranean outflow region at (a) 102 and (b) $845 \mathrm{~m}$ in the open-strait experiment, and at (c) 102 and (d) $845 \mathrm{~m}$ in the closed-strait experiment. Note the use of different vector scales for the two depth levels. Vectors are plotted at every second grid point in both the zonal and meridional directions. 
ranean salt tongue, see summaries in Spall (1999) and Stephens and Marshall (1999).

In most studies, however, the specification of an appropriate eastern boundary condition (to allow a mass flux of MW into the basin) is crucial in obtaining a realistic salinity tongue. This is also a conclusion drawn from the modeling study by Gerdes et al. (1999), who examined the effects of various processes on the largescale spreading of the MW using an ocean general circulation model of the North Atlantic with a simplified geometry and idealized forcing functions. They demonstrated that the direct input of MW equivalent to the exchange flux between the Atlantic and Mediterranean is key to the establishment of a current system that carries the MW westward into the basin interior and northward along the eastern boundary. Other processes (e.g., salt fingering) act to modify the details of the salinity tongue.

We have shown that the OCCAM model allows a realistic flux of MW at the eastern boundary through the strait. It does not, however, include doublediffusive salt fingering. We show in Fig. 10a the salinity distribution at $845 \mathrm{~m}$ (middepth of level 16) in the main experiment. As discussed in the previous section, direct input of the MW reaches to this depth in the Gulf of Cadiz. Westward and northward advective pathways are evident, and especially the salt tongue extends far into the western basin. On the level below (level 17, middepth at $989 \mathrm{~m}$ ), the salinity tongue is only marginally weaker. On deeper levels (levels 18-20, depth range 1068-1616 m), similar patterns of salinity distribution are also present, though the magnitude decreases quickly with depth.

The salinity climatology of Levitus et al. (1994) is interpolated onto the model grid, and the distribution at $1150 \mathrm{~m}$ (middepth of level 18) where the MW has the strongest signature is shown in Fig. 10b. Below this level, the strength of the salinity tongue decreases sharply. Above this level (levels 16 and 17), the distribution is very similar in the eastern basin except that the highest salinity ( $>36.2 \mathrm{psu}$ ) is not present near the boundary. In the western basin, the salinity is higher on the shallower levels. For example, the 35.2-psu contour lines intersect $70^{\circ} \mathrm{W}$ at $25^{\circ}$ and $37^{\circ} \mathrm{N}$ on level 16 .

The model's salinity tongue is stronger than the climatology of Levitus et al. (1994). There is also more structure in the model salinity pattern related to the advective fields, whereas the climatology appears as a smooth field reflecting a strong diffusive component, which could be due to smoothing in the making of the climatology.

The velocity fields at the MW depth in the model
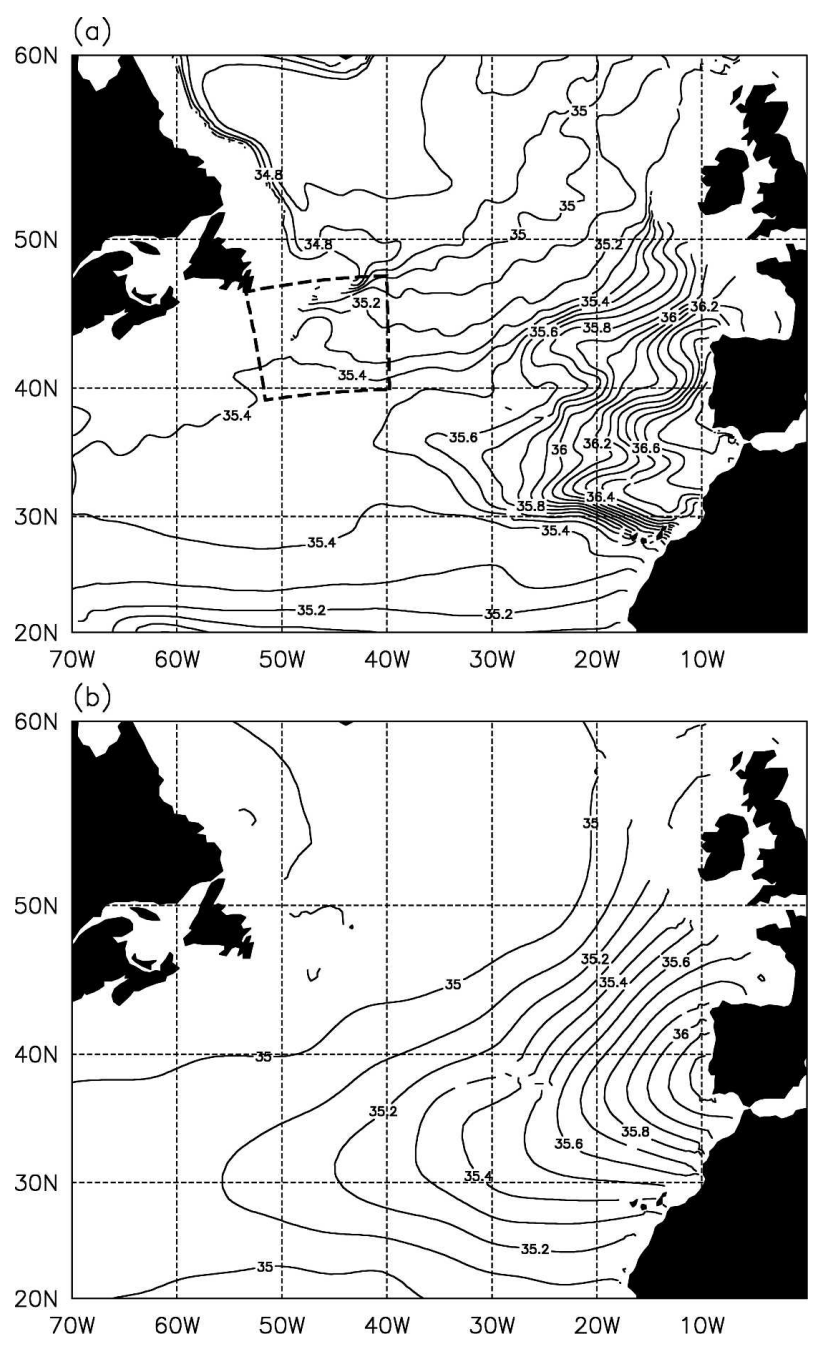

FIG. 10. Salinity distribution at the core depth of the MW: (a) $845 \mathrm{~m}$ in the open-strait experiment and (b) $1150 \mathrm{~m}$ in Levitus et al. (1994).

experiments are shown in Fig. 11. (The details of the flow field in the region of the Gulf of Cadiz are shown in Figs. 9b,d.) In the vicinity of the Gulf of Cadiz, while the closed-strait experiment shows little current structure (Fig. 11b), we see clearly the three main current branches in the open-strait experiment (Fig. 11a): the northward flow along the Portuguese coast, the westward flow away from Cape St. Vincent, and the southward flow along the African continental shelf, which turns westward just north of $30^{\circ} \mathrm{N}$. These three branches are also reflected in the salinity distribution in Fig. 10a. Part of the northward flow turns westward at Cape Finisterre $\left(\sim 43^{\circ} \mathrm{N}\right)$, creating a third westward extension of high salinity. In the central part of the basin, the continuation of the westward flow north of $30^{\circ} \mathrm{N}$ with strength of about $0.5 \mathrm{~cm} \mathrm{~s}^{-1}$ is the most noticeable 

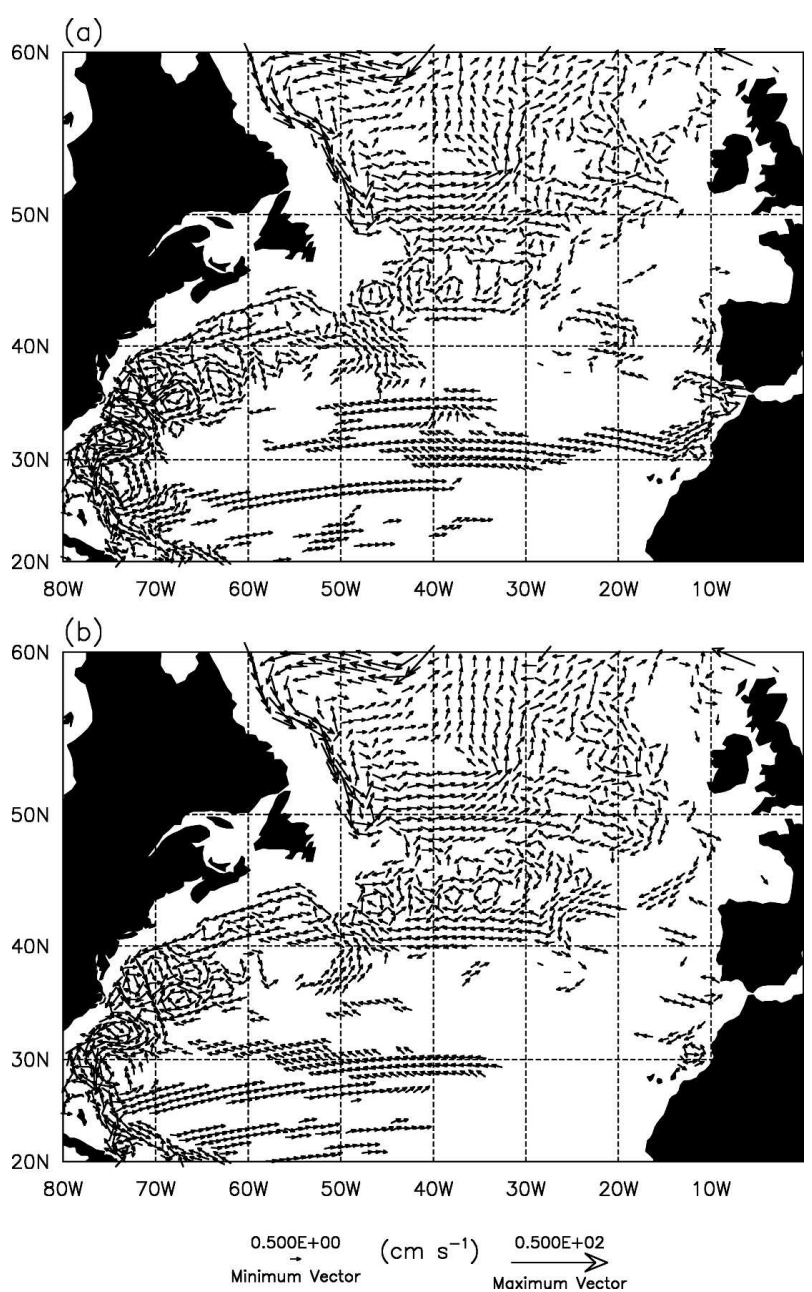

FIG. 11. Velocity field in the North Atlantic basin at $845 \mathrm{~m}$ for the (a) open-strait and (b) closed-strait experiments. Vectors are plotted at every third grid point in both the zonal and meridional directions.

feature of the flow field. Near $40^{\circ} \mathrm{W}$, part of this current continues to the western boundary and eventually joins the DWBC to travel south (we shall call this the southward pathway of the MW even though a substantial part of its journey is westward), the rest, experiencing strong eastward and westward orientations near $35^{\circ} \mathrm{N}$, moves generally in the northwestward direction to the Grand Banks off Newfoundland, where it splits to a northeastward component and a westward branch. In Fig. 10a, the signatures of this current system can be seen in the shape of the salinity contours in the central and western basin (note the orientations of the 35.3 and 35.4 contours near $\left.40^{\circ} \mathrm{N}, 50^{\circ} \mathrm{W}\right)$.

After the split near the Grand Banks, the northeastward component of the current enters an upwelling region. The vertical transport, $w_{\text {tran }}(z)$, computed for the

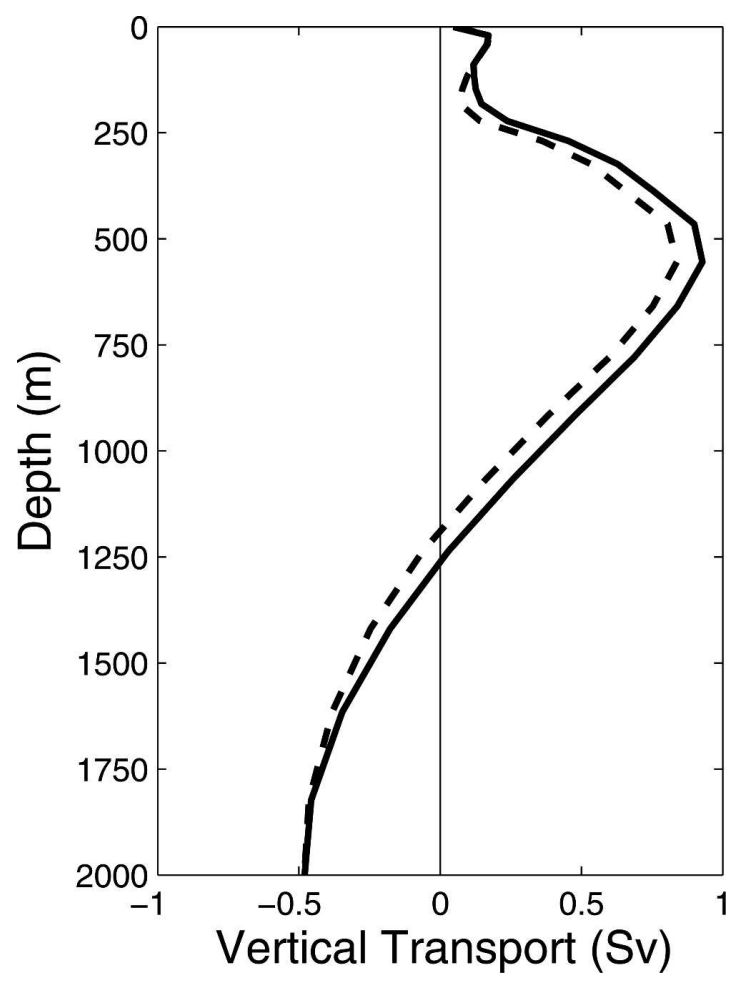

FIG. 12. Mean vertical transport $w_{\text {tran }}(z)$ in the region of the Grand Banks (area marked in Fig. 10a) for the open-strait (solid curve) and closed-strait (dashed curve) experiments.

enclosed region at the Grand Banks (the area within the thick dashed lines in Fig. 10a), shows that there is substantial upwelling above the depth of $1200 \mathrm{~m}$ in both open-strait and closed-strait experiments (Fig. 12), only that the upwelling is a little stronger when the strait is open (the continuous line); the maximum is at $555 \mathrm{~m}$. Such upwelling is expected to bring saline MW from depth to the upper ocean. Indeed, the salinity difference between the open-strait and closed-strait experiments shows a pronounced positive anomaly at $45^{\circ} \mathrm{N}$, $47^{\circ} \mathrm{W}$ from the surface to about $1000 \mathrm{~m}$ (Fig. 13). In the upper ocean (e.g., 425 m, Fig. 14), this positive salinity anomaly is carried northeastward in the NAC to reach the eastern boundary. We shall call this the indirect northward pathway of the MW.

We make two remarks about Figs. 13 and 14. In Fig. 13 , there is a deeper positive anomaly centered at 1326 $\mathrm{m}$ (middepth of level 19) near $41^{\circ} \mathrm{N}$. This is not a salinity maximum in the open-strait experiment. It results from the faster weakening of the salinity tongue on this level in the closed-strait experiment relative to the levels above and below. Over time, the positive anomaly is expected to increase on the nearby levels too as the salinity tongue weakens in the closed-strait experiment. 


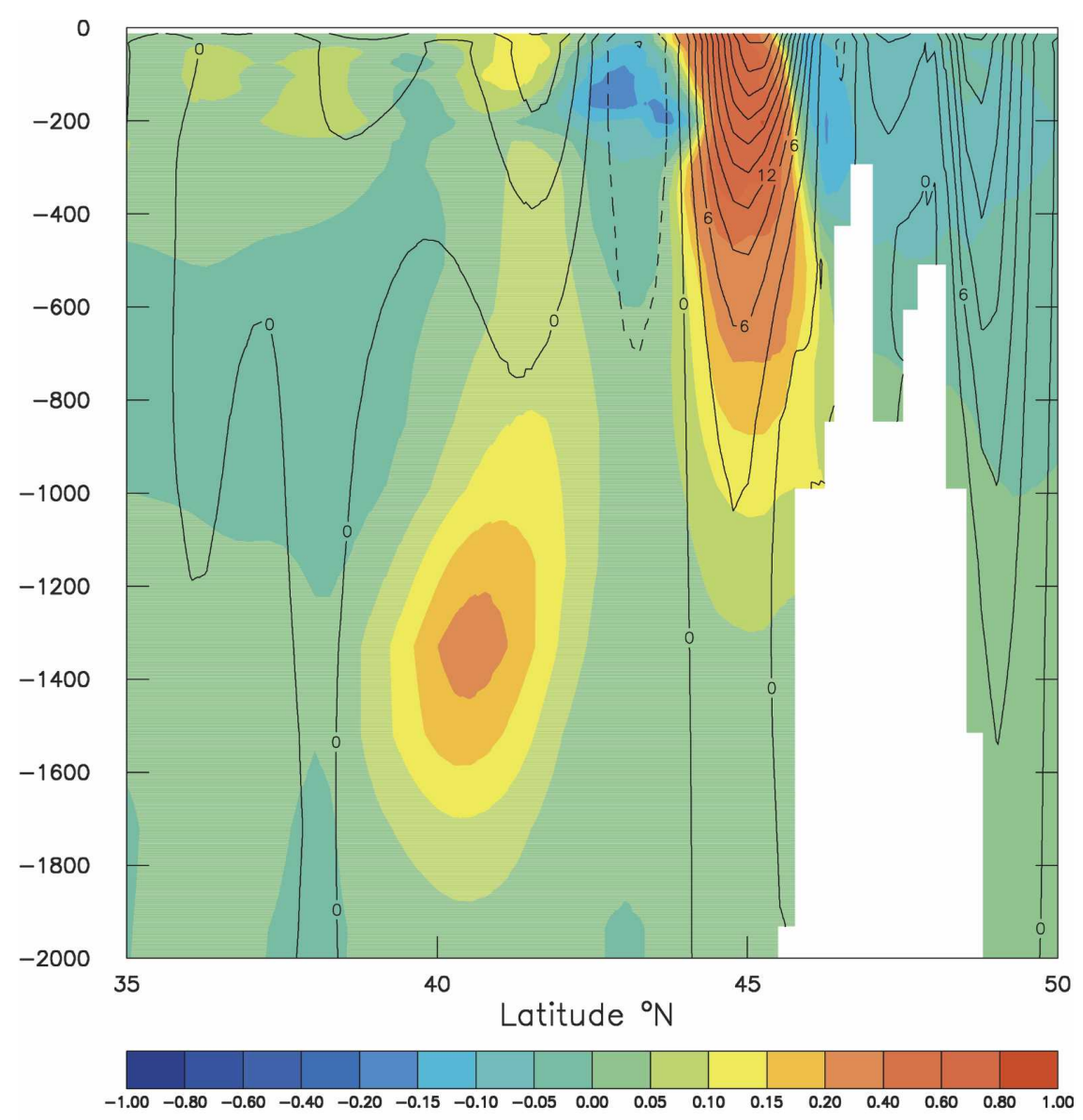

FIG. 13. Salinity difference (psu) between the open-strait and closed-strait experiments along $47^{\circ} \mathrm{W}$. Eastward velocity $\left(\mathrm{cm} \mathrm{s}^{-1}\right)$ is contoured.

In Fig. 14, there is a positive salinity anomaly at the eastern boundary extending northward from the Gulf of Cadiz. This is created by the high salinity influence of the MW in the open-strait experiment and the lack of it in the closed-strait experiment. The presence of this anomaly is consistent with the hypothesis of Mauritzen et al. (2001) that the salinity of the NACW is influenced by the saline MW through an upward salinity flux in the Gulf of Cadiz.

At $50^{\circ} \mathrm{N}$ (Fig. 15 ), the positive salinity anomaly advected from the west in the NAC occupies the depth range from 200 to $600 \mathrm{~m}$ and is clearly separated from a deeper and larger anomaly near $1000 \mathrm{~m}$ against the eastern boundary. This deeper anomaly is a result of the northward spreading of the MW directly from the Gulf of Cadiz carried by the eastern boundary undercurrent (therefore, the direct northward pathway). These two salinity anomalies fade away beyond $53^{\circ} \mathrm{N}$, owing to the relatively short integration length when compared with the advective time scales.
To give an idea of the advective time scales in relation to the model integration length, we show in Fig. 16 the time evolution of salinity at three locations following the indirect northward pathway for both the openstrait and closed-strait experiments. At the western end of the Gulf of Cadiz $\left(36^{\circ} \mathrm{N}, 9.5^{\circ} \mathrm{W}, 845 \mathrm{~m}\right)$, salinity in the open-strait experiment (solid curve in Fig. 16a) increases from year 8 to 18 and remains steady thereafter, whereas in the closed-strait experiment (dotted curve in Fig. 16a), salinity begins to decrease sharply within one year of closing the strait. Near the entrance to the upwelling region at the Grand Banks $\left(41^{\circ} \mathrm{N}, 45^{\circ} \mathrm{W}, 845\right.$ $\mathrm{m})$, the decrease in salinity in the closed-strait experiment does not begin until approximately year 19 (more than 10 years after the closing of the strait, Fig. 16b). In the upper ocean of the northeast Atlantic $\left(50^{\circ} \mathrm{N}, 20^{\circ} \mathrm{W}\right.$, $425 \mathrm{~m}$ ), a decline in salinity in the closed-strait experiment is evident only toward the end of the integration period (from year 23, Fig. 16c). As shown in Fig. 14, the positive salinity anomaly in the NAC system does not 

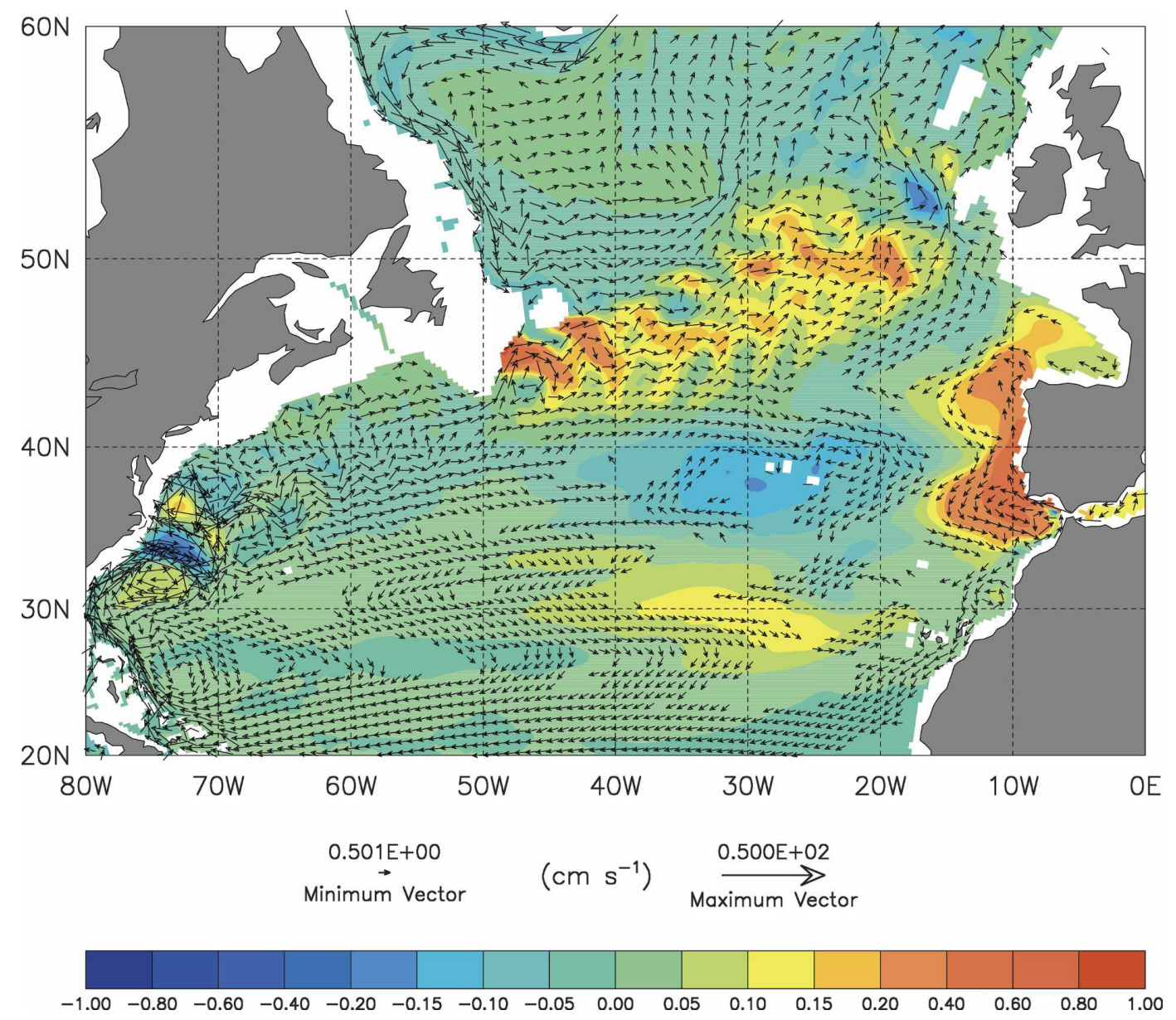

FIG. 14. As in Fig. 13 but at $425 \mathrm{~m}$, with velocity vectors plotted at every third grid point in both the zonal and meridional directions.

extend much beyond this point. A longer integration would have been desirable.

\section{b. Particle tracking of the Mediterranean Water}

To quantify the transport of the MW in each of the major pathways in the model, we make use of the particle tracking technique developed by Döös (1995) and Blanke and Raynaud (1997). An example usage of this technique in tracking water masses can be found in Drijfhout et al. (2003). Approximately 10000 particles are released at the model Strait of Gibraltar, each carrying $10^{-4} \mathrm{~Sv}$ transport of the MW. These particles are advected by the model's three-dimensional velocity field, which consists of the time-mean flow and the mean rectification of the time-dependent component in the form of bolus velocity.

Figure 17 displays the tracks of 44 randomly chosen particles two years after their release. It is to be compared with Fig. 5a of Bower et al. (1997), which shows tracks of 44 floats during A Mediterranean Undercurrent Seeding Experiment (AMUSE). Note that the float observations span 21 months from May 1993 to March 1995; the length of each of the float tracks varies from 2 to 333 days, with an average of 180 days, and thus shorter than the model trajectories shown. The model trajectories show two distinct pathways: northward along the Portuguese coast and westward from Cape St. Vincent, as well as the recirculation in the Gulf of Cadiz. These characteristics are also reflected by the float tracks. One of the major differences is that the observations show much-smaller-scale variabilities and meddy motions, which are lacking in the model trajectories because of the use of the mean flow fields for tracking and inadequate horizontal resolution to allow meddy formation. Another difference is that the model trajectories are mostly between 600 and $1000 \mathrm{dbar}$, while the float tracks are mostly between 1000 and 1200 dbar; thus the model MW resides at a shallower depth 


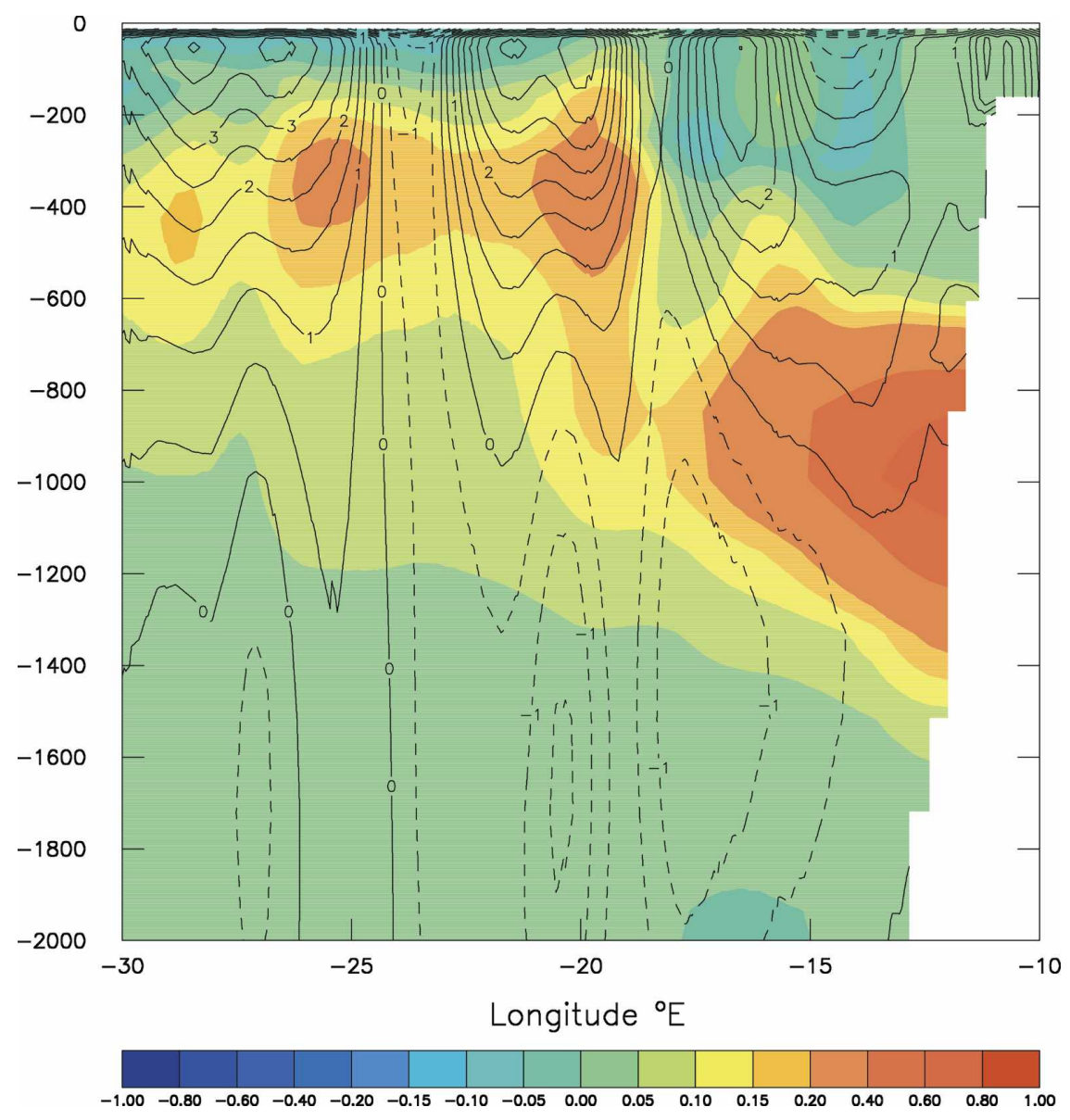

FIG. 15. As in Fig. 13 but along $50^{\circ} \mathrm{N}$. Northward velocity $\left(\mathrm{cm} \mathrm{s}^{-1}\right)$ is contoured.

than observed, as discussed earlier. It is noted in Bower et al. (1997) that none of the 44 floats stayed close to the continental slope north of $40^{\circ} \mathrm{N}$. This is not the case for the model particles. As will be seen later, many particles stayed within the continental slope and traveled to $60^{\circ} \mathrm{N}$ and beyond. The southward flow along the African coast is not shown by the 44 particles because of the short duration, although one particle is beginning to make its journey southward along the boundary.

By marking the trajectories of all particles to the point when they reach either $60^{\circ}$ or $10^{\circ} \mathrm{N}$ (or farther south if desired), a transport streamfunction of the MW may be constructed by integrating the transport carried by all of the trajectories along latitude lines (starting from the western boundary) from all depths within the domain bounded by the three sections $\left(60^{\circ} \mathrm{N}, 10^{\circ} \mathrm{N}\right.$, and the Strait of Gibraltar) and the landmasses. The resultant picture is shown in Fig. 18, with the zero contour separating the trajectories that exit the domain at $60^{\circ}$ (dashed contours) and $10^{\circ} \mathrm{N}$ (continuous contours). This transport streamfunction confirms the three major MW pathways described already. Approximately 63\%
(0.69 Sv) take the southward pathway, 25\% (0.27 Sv) are found in the direct northward pathway, and $12 \%$ $(0.13 \mathrm{~Sv})$ are involved in the indirect northward pathway. The effect of eddies (in the form of bolus velocity) is to increase the northward transport by about $0.1 \mathrm{~Sv}$ at the expense of the southward transport.

The exact pathways taken by the particles are varied. For example, some of the particles involved in the indirect northward pathway travel all the way to the western boundary and upwell there before turning back eastward with the Gulf Stream and the NAC. Among the particles in the direct northward pathway, some leave the coast near Cape Finisterre $\left(\sim 43^{\circ} \mathrm{N}\right)$ to travel westward, then take an anticyclonic circuit before heading north again. A small proportion of the particles in the southward pathway initially move northward along the continental slope and then westward toward the western boundary.

Continuing tracking northward beyond $60^{\circ} \mathrm{N}$, some particles are seen to enter the Nordic seas and the Arctic, and others become entrained into the subpolar gyre. Three example trajectories are shown in Fig. 19. In the 

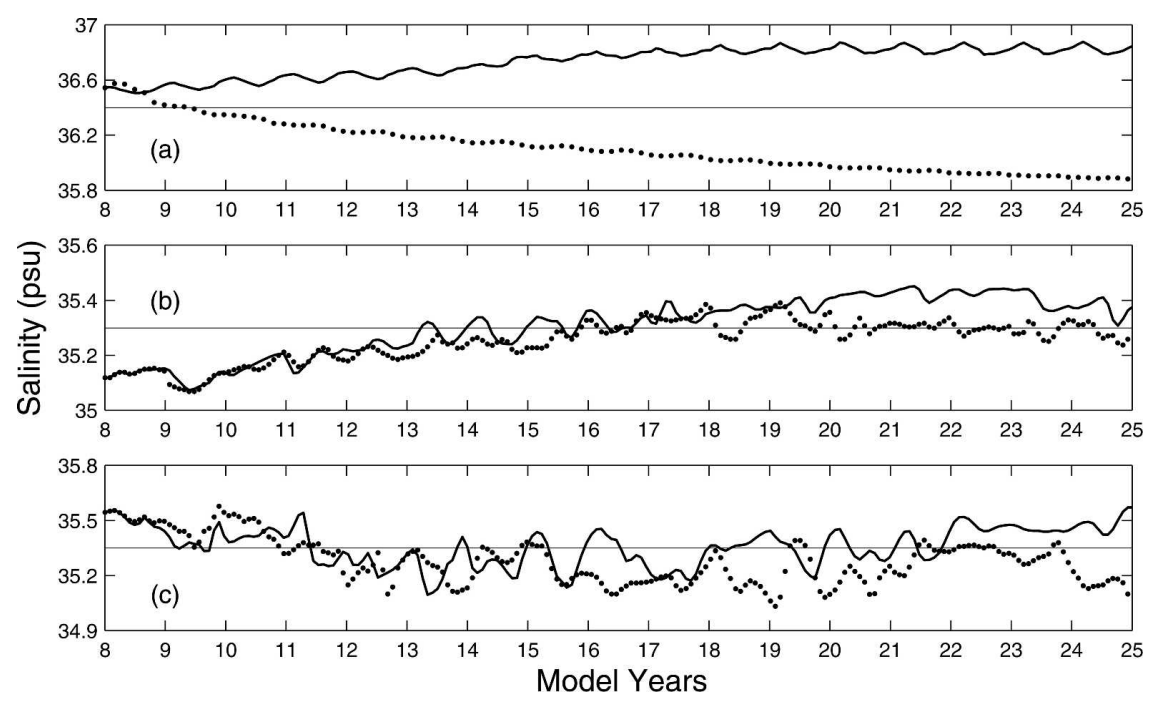

FIG. 16. Time evolution of salinity at (a) $36^{\circ} \mathrm{N}, 9.5^{\circ} \mathrm{W}, 845 \mathrm{~m}$; (b) $41^{\circ} \mathrm{N}, 45^{\circ} \mathrm{W}, 845 \mathrm{~m}$; and (c) $50^{\circ} \mathrm{N}, 20^{\circ} \mathrm{W}, 425 \mathrm{~m}$ for the open-strait (solid curves) and closed-strait (dotted curves) experiments. In (b) and (c) each dot represents a monthly snapshot; in (a) each dot represents a bimonthly snapshot for clarity.

vicinity of the Gulf of Cadiz, all three trajectories make a cyclonic loop before turning north or southwest (then west). The southward pathway is clearly shown by the trajectory (marked with "S") that travels all the way to the western boundary and then southward to cross the equator at a depth greater than $1500 \mathrm{~m}$ (in yellow). The trajectory (marked with "NE") that goes directly northward at a depth of about $1000 \mathrm{~m}$ along the eastern boundary reaches as far as Iceland. However, it does not rise in the water column to enter the Nordic seas, as would have been expected from Reid's (1979) deep source hypothesis. Instead, it moves westward and becomes entrained into the lower part of the subpolar gyre. The rest of its journey (in red) is reminiscent of the eastward and southward pathway of the Labrador Sea Water (Talley and McCartney 1982). The third trajectory (marked with "NW") depicts the indirect northward pathway of the MW. It travels in a generally northwestward direction in the central Atlantic to the Grand Banks and rises in the water column, as expected (its color changes from green to blue). It then follows the NAC northeastward and enters the Nordic seas. This trajectory is a good demonstration of the shallow source hypothesis of McCartney and Mauritzen (2001). Eventually, this trajectory exits the Nordic seas through Denmark Strait at a depth of about $300 \mathrm{~m}$ within the strait overflow water, descends to the deep ocean, and takes several downward spiral circuits around the subpolar gyre before heading southward, following a path similar to the red trajectory.

Finally, all particles eventually exit the Atlantic at the southern boundary $\left(\sim 34^{\circ} \mathrm{S}\right)$ at varying time scales. The particles in the southward pathway take on average $270 \mathrm{yr}$ to reach $34^{\circ} \mathrm{S} ; 90 \%$ arrive within $850 \mathrm{yr}$. For the northward-traveling particles, first it takes on average about $53 \mathrm{yr}$ for them to reach $60^{\circ} \mathrm{N} ; 90 \%$ arrive within $93 \mathrm{yr}$. Then, some of the particles become entrained into the subpolar gyre before returning south; others enter the Nordic seas or even visit the Arctic to be transformed into the NADW before returning south in the DWBC. The time it takes for these particles to reach $34^{\circ} \mathrm{S}$ is considerably longer-330 yr on average, and $900 \mathrm{yr}$ for $90 \%$ of the particles to arrive at the southern boundary.

\section{c. Discussion}

The northward spreading of the MW in an eastern boundary undercurrent as far as Porcupine Bank $\left(\sim 51^{\circ} \mathrm{N}\right)$ has ample support from observations (e.g., Zenk and Armi 1990; Pingree and Le Cann 1990; Hill and Mitchelson-Jacob 1993; Daniault et al. 1994; Arhan et al. 1994). In the closed-strait experiment, flow along the eastern boundary at depth exhibits strong seasonal variability with northward flow mainly in summer and autumn and southward flow in winter and spring. As a result, the annual average is close to zero. In the openstrait experiment, the seasonal variability still persists except that the intrusion of the MW enhances the northward component and leaves a net northward flow along the boundary

In comparison, direct observations of the flow field in the central Atlantic at the MW depth are sparse and 


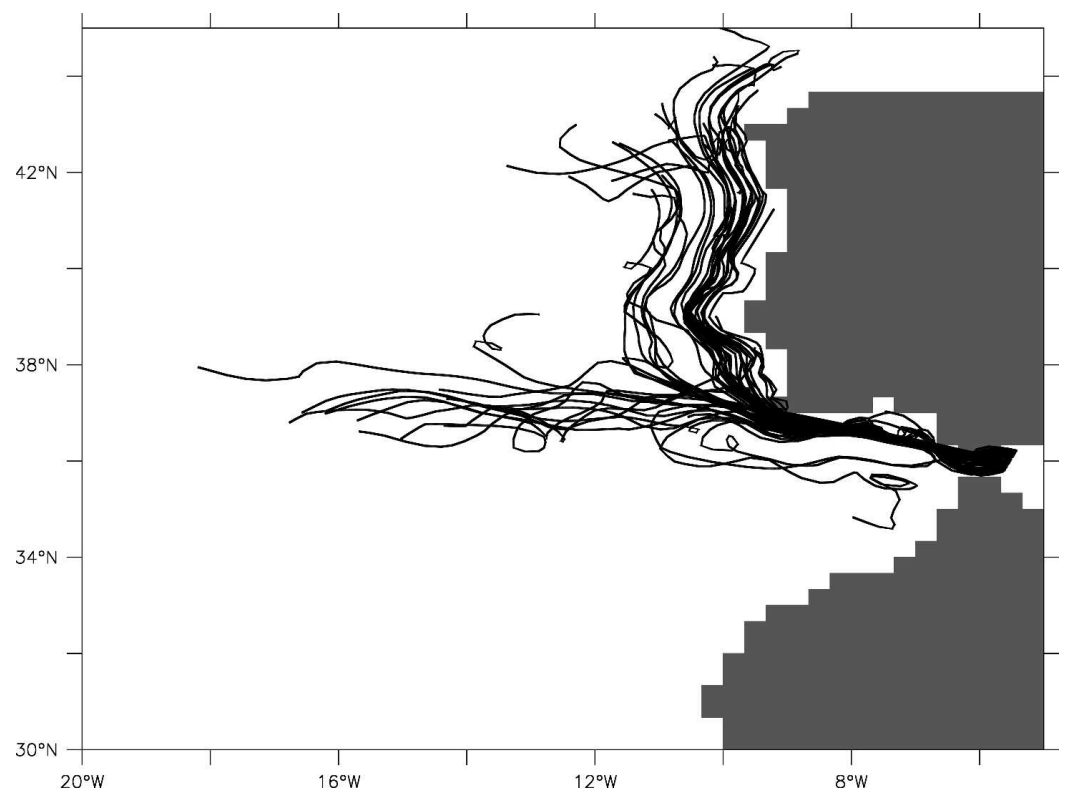

FIG. 17. Trajectories of 44 randomly chosen particles two years after their release in the MW at the model Strait of Gibraltar.

show little consistency. Inference of a westward pathway of the MW is usually based on the characteristics of the salinity distribution; that is, in the presence of lateral mixing, the westward extension of the salt tongue must be accomplished by advection (e.g., Wüst 1935; Arhan 1987; Hogg 1987). Westward flow along the salt tongue near $30^{\circ} \mathrm{N}$ has been predicted by previous mod- eling studies (Stanev 1992; Bogden et al. 1993). Bogden et al. (1993) also found support for a westward flow from measurements at locations situated in the western basin (e.g., Owens 1991), in the central Atlantic (Fu et al. 1982), and in the eastern basin (Schmitz et al. 1988; Zenk and Müller 1988). The 7-yr current-meter record analyzed by Zenk and Müller (1988) showed a mean

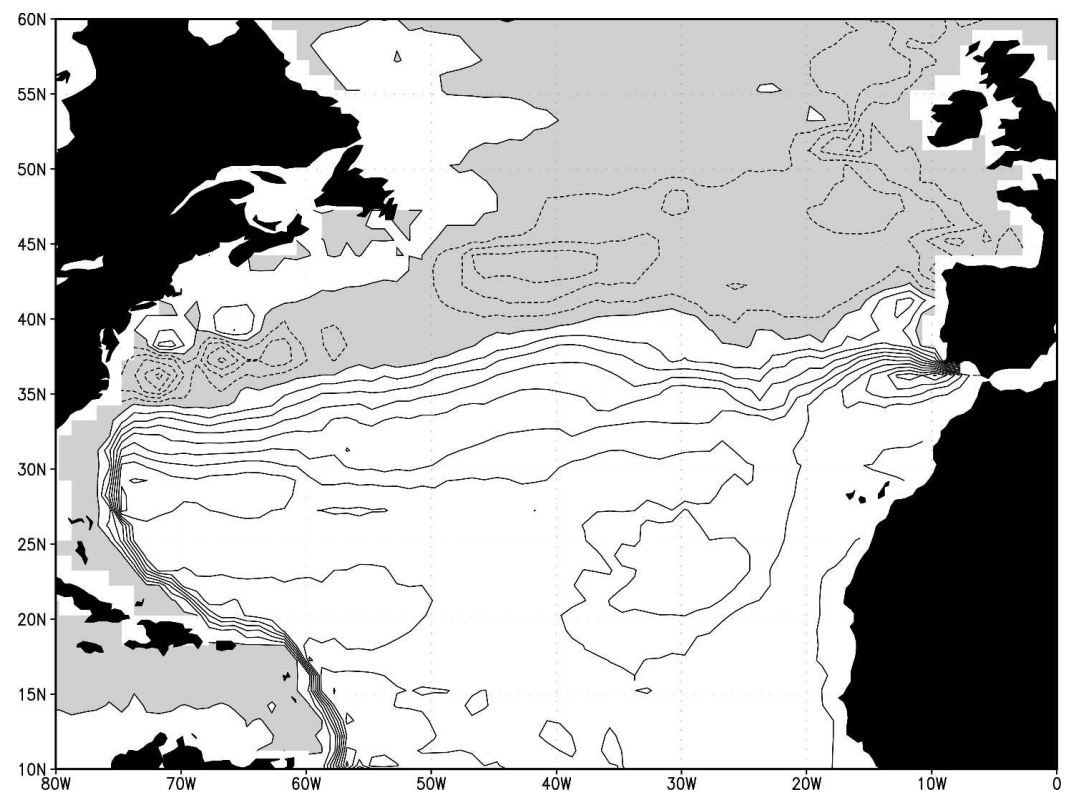

FIG. 18. Transport streamfunction of the MW computed by integrating all the trajectories. Contour interval: $0.1 \mathrm{~Sv}$. 


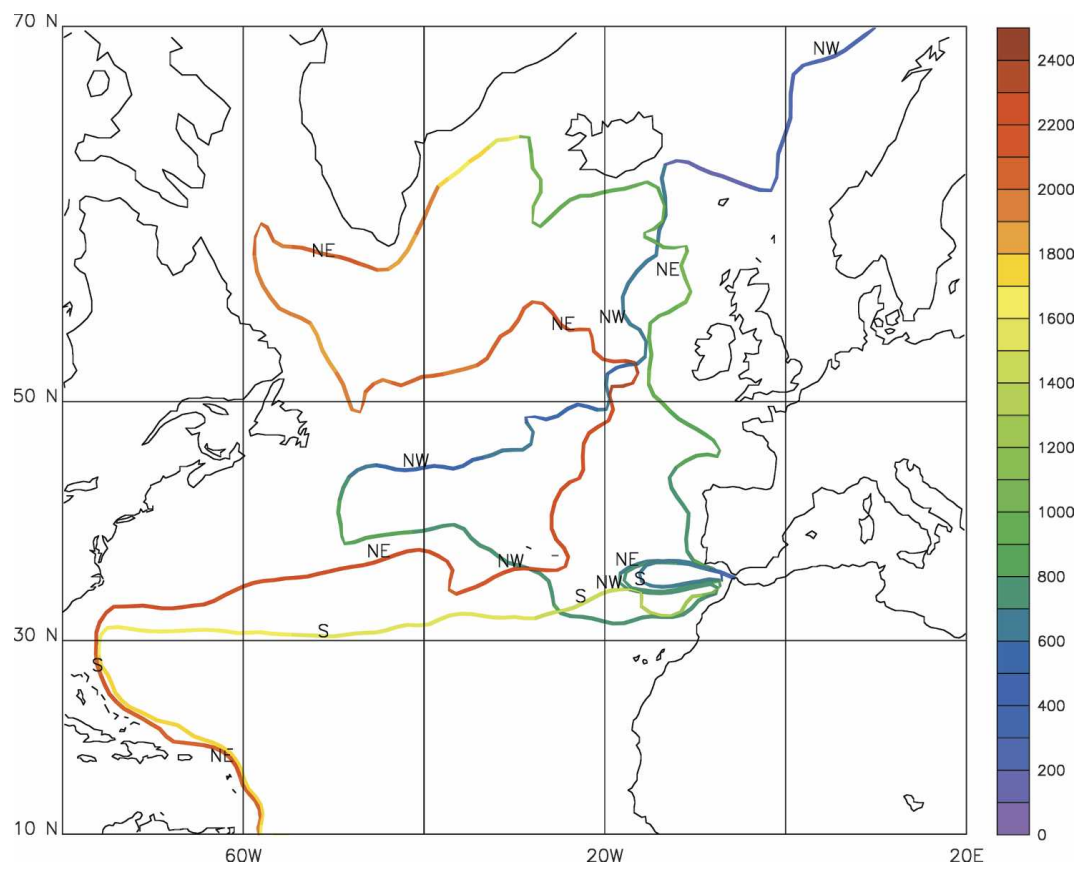

FIG. 19. Pathways of three example trajectories: the southward path is marked with "S," the direct northward path is marked with "NE," and the indirect northward path is marked with "NW."

westward component of $0.30 \pm 0.79 \mathrm{~cm} \mathrm{~s}^{-1}$ (and northward $0.15 \pm 0.61 \mathrm{~cm} \mathrm{~s}^{-1}$ ), which was considered, however, not to be significantly different from zero. The current meter was located at $33^{\circ} \mathrm{N}, 22^{\circ} \mathrm{W}$ and $1000-\mathrm{m}$ depth. Sparrow et al. (2002) also showed weak flows with little directional coherence in the eastern basin south of $36^{\circ} \mathrm{N}$ through the analysis of float trajectories. Modeling studies by Paillet and Mercier (1997) and

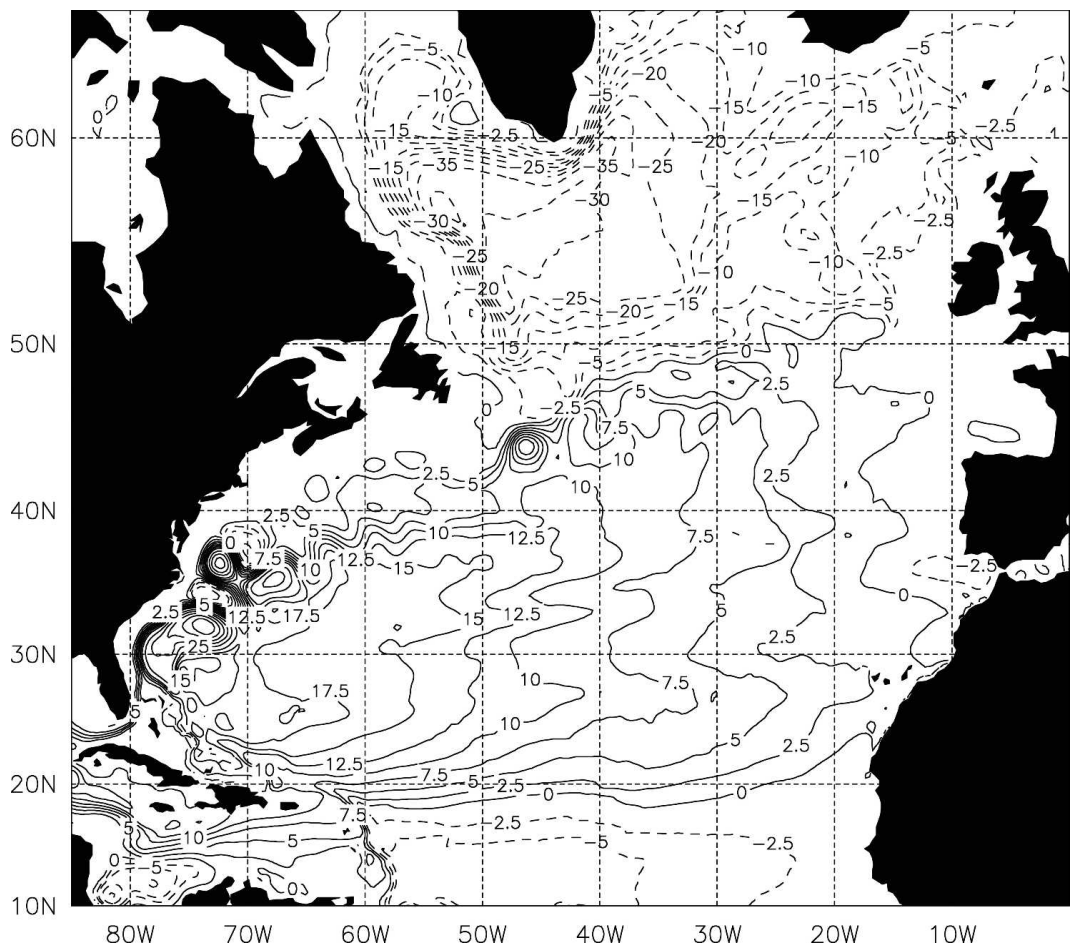

FIG. 20. Horizontal transport streamfunction (Sv) of the open-strait experiment. 
Iorga and Lozier (1999b) do not suggest a significant westward pathway.

These apparent differing results clearly point to difficulties in determining the flow field at depth. Although we do not wish to assert the existence of a westward current purely based on this one model realization, the presence of this current system does seem to be in response to the influx of the MW in the model; it is absent in the closed-strait experiment. It is worth noting that the westward current in the present model simulation is very weak $\left(\sim 0.5 \mathrm{~cm} \mathrm{~s}^{-1}\right)$. Such a small signal may not be easily detected from field measurements, as the observed flow field is likely to contain much mesoscale variability, especially fast-moving meddies. Even in the model, the flow at the MW depth only appears as minor modifications in the model's depthaveraged flow field (the horizontal transport streamfunction, Fig. 20), such as the cyclonic circulation in the Gulf of Cadiz (2.5 Sv in strength) and the zigzag feature shown by the 7.5-15-Sv contours in the region of 30$40^{\circ} \mathrm{N}$ and $35-55^{\circ} \mathrm{W}$. The strengths of the subpolar and subtropical gyres, approximately 35 and $30 \mathrm{~Sv}$, respectively, are comparable with previous modeling studies (e.g., Willebrand et al. 2001).

The model shows that some of the MW, after leaving the Gulf of Cadiz, first flows southward along the African coast before turning west (Fig. 11a). Mittelstaedt (1989) observed southward transport of the MW at $32^{\circ} \mathrm{N}$ at depth $1000-1400 \mathrm{~m}$. Southward flow of the MW might also be present at lower latitudes $\left(17^{\circ}-26^{\circ} \mathrm{N}\right)$ along the coast (Barton 1989). No MW in the model goes beyond the Canary Islands $\left(\sim 28^{\circ} \mathrm{N}\right)$.

The model suggests that a large proportion of the MW that travels westward reaches the western boundary and joins the DWBC to flow southward. At present, we are not aware of any observations or previous modeling studies to support or disregard such a possibility. On the other hand, if there is a direct advective pathway of the MW across the basin, as suggested by this study and previous modeling studies (Stanev 1992; Bogden et al. 1993), then the MW must deflect northward or southward when it reaches the boundary. It is possible that the use of horizontal and vertical tracer diffusion in the model may have allowed too much MW to be entrained into the DWBC through implicit diapycnal mixing. We may speculate that more MW will move northward to be entrained into the Gulf Stream and the NAC if isopycnal mixing is used in the model.

\section{Summary}

The narrowness of the Strait of Gibraltar and the complex dynamics that control the downslope evolu- tion of the dense Mediterranean outflow present great difficulties in ocean modeling. In the present model, the exchange through the Strait of Gibraltar between the Atlantic and the Mediterranean is explicitly included, but there is no special treatment of the downslope evolution of the dense overflow.

We find that the model produces an exchange flux of around $1 \mathrm{~Sv}$ at the Strait of Gibraltar, which is comparable to estimates derived from field measurements. However, the temperature of the Mediterranean outflow is too high and this results in a model outflow that is less dense than observed. Downstream from the strait, the model MW mixes strongly with the ambient NACW in the initial descent down the model steps, doubling its transport and reducing its density and salinity. In nature, intense and localized mixing of the MW and the NACW also occurs at the initial descent of the continental slope through an entrainment stress. In the model, mixing is by means of convective adjustment and diapycnal diffusion, which result in excessive mixing of the water masses. At the western end of the Gulf of Cadiz, the MW in the model reaches a maximum depth of about $1000 \mathrm{~m}$ with the highest salinity near 850 $\mathrm{m}$ (the core depth), about $200 \mathrm{~m}$ shallower than in reality. The high temperature of the outflow and inadequate representation of the entrainment mixing associated with the dense water plume are the major causes of the insufficient vertical penetration of the MW in the model.

In future studies, we need to pay special attention to the modeling of the Mediterranean Sea to ensure the correct MW properties. Improving the representation of the physics of descending dense water plume is also necessary. At present, there are remedies to overcome this model defect. In case of too much mixing (usually associated with models with geopotential as vertical coordinate, such as the one used in this study), a bottom boundary layer model such as the one by Beckmann and Döscher (1997) or Killworth and Edwards (1999) may be embedded to allow the dense flow to descend to a greater depth. In case of insufficient mixing (often associated with models with potential density as vertical coordinate), the use of a Richardson numberdependent diapycnal diffusion scheme can be effective in providing sufficient mixing for the overflow, as demonstrated by Hallberg (2000). These schemes are being implemented and tested (e.g., Papadakis et al. 2003), and the outlook is promising.

In the mean time, for studies of ocean mesoscale characteristics that do not require long integrations, the representation of the MW in ocean models may be improved by the combination of increased horizontal resolution to resolve the width of the strait and the use 
of a weak restoring condition in the Gulf of Cadiz to achieve a realistic depth of the MW tongue. For example, Drillet et al. (2005) reported a realistic exchange rate at the Strait of Gibraltar (0.84 Sv), many aspects of the observed meddy characteristics, and an MW tongue at $1100 \mathrm{~m}$ in a high-resolution model of the North Atlantic and the Mediterranean Sea. Without the restoring, however, the MW was found to settle at about $800 \mathrm{~m}$.

Although the MW in the present study does not reach as deep as desired, the current system generated by its intrusion at middepth of the ocean is unmistakable. Away from the Gulf of Cadiz, three principal pathways of the MW are identified-the direct northward path along the eastern boundary, the (westward then) southward path along the western boundary, and the indirect northward path. In all three cases, the MW finds its way to become part of the NADW to exit the basin at the southern boundary.

The indirect northward path found in the model appears as a weak but continuous westward current at the core depth of the MW that runs from the eastern boundary to the central Atlantic just north of $30^{\circ} \mathrm{N}$ and then turns northwestward to reach an upwelling region at the Grand Banks off Newfoundland. The existence of such a current system in the model allows the MW to rise from depth to the ocean upper layer at the Grand Banks, to become a constituent of the NAC system, which increases the salinity of the near-surface waters in the northern North Atlantic and possibly in the Nordic seas, as envisaged by McCartney and Mauritzen (2001), though the proportion of the MW taking this pathway is small in the present model.

The presence of the MW in the inflow to the Nordic seas is conjectured by Reid (1979) to contribute to the preconditioning for the formation of the NADW there. Ideally we would like to know to what extent the saline MW might influence the convection and, therefore, the formation of the NADW in the Nordic seas. Regrettably, the model experiments presented here are not sufficient to explore this question. No significant differences are found in the strength of the meridional overturning circulation between the open-strait and closedstrait experiments. Simulations of 100 years or longer are necessary. This is suggested by Hecht et al. (1997), who examined the sensitivity of the North Atlantic circulation to different ways of specifying the MW and found that the meridional overturning circulation collapses over a time of 340 years if no MW is included.

Acknowledgments. We are very grateful to Harry Bryden for his interest in the study and his valuable comments on the draft manuscript. We thank Yann
Friocourt for making the trajectory program suitable for tracking the Mediterranean Water in the OCCAM model. We greatly appreciate the comments by Anne Marie Treguier and an anonymous reviewer, which have helped to improve the manuscript. This manuscript was written while YJ was a visitor at the International Pacific Research Center (IPRC). The facilities provided by the IPRC are much appreciated.

\section{REFERENCES}

Arakawa, A., 1966: Computational design for long-term numerical integration of the equations of fluid motion: Twodimensional incompressible flow. Part 1. J. Comput. Phys., 1, 119-143.

Arhan, M., 1987: On the large scale dynamics of the Mediterranean outflow. Deep-Sea Res., 34, 1187-1208.

_ A. Colin de Verdière, and L. Mèmery, 1994: The eastern boundary of the subtropical North Atlantic. J. Phys. Oceanogr., 24, 1295-1316.

Baringer, M. O., and J. F. Price, 1997a: Mixing and spreading of the Mediterranean outflow. J. Phys. Oceanogr., 27, 1654 1677.

_ Mediterranean outflow. J. Phys. Oceanogr., 27, 1678-1692.

Barton, E. D., 1989: The poleward undercurrent on the eastern boundary of the subtropical North Atlantic. Poleward Flows Along Eastern Ocean Boundaries, S. J. Neshyba et al., Eds., Vol. 34, Coastal and Estuarine Studies, Springer-Verlag, 8292.

Beckmann, A., and R. Döscher, 1997: A method for improved representation of dense water spreading over topography in geopotential-coordinate models. J. Phys. Oceanogr., 27, 581591.

Blanke, B., and S. Raynaud, 1997: Kinematics of the Pacific Equatorial Undercurrent: An Eulerian and Lagrangian approach from GCM results. J. Phys. Oceanogr., 27, 1038-1053.

Bogden, P. S., R. E. Davis, and R. Salmon, 1993: The North Atlantic circulation: Combining simplified dynamics with hydrographic data. J. Mar. Res., 51, 1-52.

Bower, A. S., L. Armi, and I. Ambar, 1997: Lagrangian observations of meddy formation during A Mediterranean Undercurrent Seeding Experiment. J. Phys. Oceanogr., 27, 25452575.

Bryan, K., 1969: A numerical method for the study of the circulation of the World Ocean. J. Comput. Phys., 4, 347-376.

Bryden, H. L., and H. M. Stommel, 1982: Origins of the Mediterranean outflow. J. Mar. Res., 40 (Suppl.), 55-71.

— J. J. Candela, and T. H. Kinder, 1994: Exchange through the Strait of Gibraltar. Progress in Oceanography, Vol. 33, Pergamon, 201-248.

Candela, J., 2001: Mediterranean Water and global circulation. Ocean Circulation and Climate: Observing and Modelling the Global Ocean, G. Siedler, J. Church, and J. Gould, Eds., Academic Press, 419-429.

Coward, A. C., P. D. Killworth, and J. R. Blundell, 1994: Tests of a two-grid World Ocean model. J. Geophys. Res., 99, 22725 22735.

Cox, M. D., 1984: A primitive equation 3-dimensional model of the ocean. NOAA/GFDL Ocean Group Tech. Rep. 1, 14 pp.

Daniault, N. J., P. Mazé, and M. Arhan, 1994: Circulation and 
mixing of the Mediterranean Water west of the Iberian Peninsula. Deep-Sea Res., 41, 1685-1714.

Döös, K., 1995: Interocean exchange of water masses. J. Geophys. Res., 100, 13 499-13 514.

Döscher, R., C. W. Böning, and P. Herrmann, 1994: Response of circulation and heat transport in the North Atlantic to changes in thermohaline forcing in northern latitudes: A model study. J. Phys. Oceanogr., 24, 2306-2320.

Drijfhout, S. S., P. de Vries, K. Döös, and A. C. Coward, 2003: Impact of eddy-induced transport on the Lagrangian structure of the upper branch of the thermohaline circulation. $J$. Phys. Oceanogr., 33, 2141-2155.

Drillet, Y., R. Bourdallé-Badie, L. Siefridt, and C. Le Provost, 2005: Meddies in the Mercator North Atlantic and Mediterranean Sea eddy-resolving model. J. Geophys. Res., 110, C03016, doi:10.1029/2003JC002170.

Fu, L.-L., T. Keffer, P. P. Niiler, and C. Wunsch, 1982: Observations of mesoscale variability in the western North Atlantic: A comparative study. J. Mar. Res., 40, 809-848.

Gascard, J.-C., and C. Richez, 1985: Water masses and circulation in the western Alboran Sea and in the Strait of Gibraltar. Progress in Oceanography, Vol. 15, Pergamon, 157-216.

Gerdes, R., and C. Köberle, 1995: On the influence of DSOW in a numerical model of the North Atlantic general circulation. J. Phys. Oceanogr., 25, 2624-2642.

,-- , A. Beckmann, P. Herrmann, and J. Willebrand, 1999: Mechanisms for spreading of Mediterranean Water in coarseresolution numerical models. J. Phys. Oceanogr., 29, 16821700.

Hallberg, R., 2000: Time integration of diapycnal diffusion and Richardson number-dependent mixing in isopycnal ocean models. Mon. Wea. Rev., 128, 1402-1419.

Hecht, M., W. Holland, V. Artale, and N. Pinardi, 1997: North Atlantic model sensitivity to Mediterranean Waters. Assessing Climate Change: Results from the Model Evaluation Consortium for Climate Assessment, W. Howe and A. Henderson-Sellers, Eds., Gordon and Breach, 169-191.

Hill, A. E., and E. G. Mitchelson-Jacob, 1993: Observations of a poleward-flowing saline core off the continental slope west of Scotland. Deep-Sea Res., 40, 1521-1527.

Hogg, N. G., 1987: A least-squares fit of the advection-diffusion equations to Levitus atlas data. J. Mar. Res., 45, 347-375.

Iorga, M. C., and M. S. Lozier, 1999a: Signatures of the Mediterranean outflow from a North Atlantic climatology. 1. Salinity and density fields. J. Geophys. Res., 104, 25 985-26 009.

— from a North Atlantic climatology. 2. Diagnostic velocity fields. J. Geophys. Res., 104, 26 011-26 029.

Jia, Y., 2000: Formation of an Azores Current due to Mediterranean overflow in a modeling study of the North Atlantic. $J$. Phys. Oceanogr., 30, 2342-2358.

Killworth, P. D., and N. R. Edwards, 1999: A turbulent bottom boundary layer code for use in numerical ocean models. $J$. Phys. Oceanogr., 29, 1221-1238.

— D. Stainforth, and D. J. Webb, 1991: The development of a free surface Bryan-Cox-Semtner ocean model. J. Phys. Oceanogr., 21, 1333-1348.

Lee, M.-M., A. C. Coward, and A. J. G. Nurser, 2002: Spurious diapycnal mixing of the deep waters in an eddy-permitting global ocean model. J. Phys. Oceanogr., 32, 1522-1535.

Levitus, S., 1982: Climatological Atlas of the World Ocean. NOAA Prof. Paper 13, 173 pp. and 17 microfiche.
, and T. P. Boyer, 1994: Temperature. Vol. 4, World Ocean Atlas 1994, NOAA Atlas NESDIS 4, 117 pp.

_, R. Burgett, and T. P. Boyer, 1994: Salinity. Vol. 3, World Ocean Atlas 1994, NOAA Atlas NESDIS 3, 99 pp.

Lozier, M. S., W. B. Owens, and R. G. Curry, 1995: The climatology of the North Atlantic. Progress in Oceanography, Vol. 36, Pergamon, 1-44.

Luyten, J. R., and H. M. Stommel, 1986: Experiments with crossgyre flow patterns on a beta-plane. Deep-Sea Res., 33, 963 972.

Mauritzen, C., Y. Morel, and J. Paillet, 2001: On the influence of Mediterranean Water on the Central Waters of the North Atlantic Ocean. Deep-Sea Res., 48, 347-381.

McCartney, M. S., and C. Mauritzen, 2001: On the origin of the warm inflow to the Nordic seas. Progress in Oceanography, Vol. 51, Pergamon, 125-214.

Mittelstaedt, E., 1989: The subsurface circulation along the Moroccan slope. Poleward Flows Along Eastern Ocean Boundaries, S. J. Neshyba er al., Eds., Vol. 34, Coastal and Estuarine Studies, Springer-Verlag, 96-108.

New, A. L., S. Barnard, P. Herrmann, and J.-M. Molines, 2001: On the origin and pathway of the saline inflow to the Nordic seas: Insights from models. Progress in Oceanography, Vol. 48, Pergamon, 255-288.

Owens, W. B., 1991: A statistical description of the mean circulation and eddy variability in the northwestern Atlantic using SOFAR floats. Progress in Oceanography, Vol. 28, Pergamon, 257-303.

Özgökmen, T. M., E. P. Chassignet, and C. G. H. Rooth, 2001: On the connection between the Mediterranean outflow and the Azores Current. J. Phys. Oceanogr., 31, 461-480.

Paillet, J., and H. Mercier, 1997: An inverse model of the eastern North Atlantic general circulation and thermohaline ventilation. Deep-Sea Res., 44, 1293-1328.

Papadakis, M. P., E. P. Chassignet, and R. W. Hallberg, 2003: Numerical simulations of the Mediterranean Sea outflow: Impact of the entrainment parameterization in an isopycnic coordinate ocean model. Ocean Modell., 5, 325-356.

Parrilla, G., T. H. Kinder, and R. H. Preller, 1986: Deep and intermediate Mediterranean Water in the western Alboran Sea. Deep-Sea Res., 33, 55-88.

Pedlosky, J., 1996: Ocean Circulation Theory. Springer-Verlag, $453 \mathrm{pp}$.

Pingree, R. D., and B. Le Cann, 1990: Structure, strength and seasonality of the slope currents in the Bay of Biscay region. J. Mar. Biol. Assoc. UK, 70, 857-885.

Reid, J. L., 1979: On the contribution of the Mediterranean Sea outflow to the Norwegian-Greenland Sea. Deep-Sea Res., 26, 1199-1223.

Roberts, M. J., R. Marsh, A. L. New, and R. A. Wood, 1996: An intercomparison of a Bryan-Cox type ocean model and an isopycnic model. Part I: The subpolar gyre and high-latitude processes. J. Phys. Oceanogr., 26, 1495-1527.

Saunders, P. M., A. C. Coward, and B. A. de Cuevas, 1999: Circulation of the Pacific Ocean seen in a global ocean model: Ocean Circulation and Climate Advanced Modelling project (OCCAM). J. Geophys. Res., 104, 18 281-18 299.

Schmitz, W. J., Jr., J. F. Price, and P. L. Richardson, 1988: Recent moored current meter and SOFAR float observations in the eastern Atlantic near $32^{\circ}$ N. J. Mar. Res., 46, 301-319.

Semtner, A. J., 1974: A general circulation model for the World Ocean. Department of Meteorology, University of California, Los Angeles Tech. Rep. 9, 99 pp. 
Siefridt, L., 1994: Validation des données $E R S-1$ et des flux de surface du CEPMMT dans le contexte de la modélisation des circulations océaniques à l'échelle d'un bassin. Ph.D. thesis, Université Joseph Fourier-Grenoble I.

Smith, P. C., 1975: A streamtube model for bottom boundary currents in the ocean. Deep-Sea Res., 22, 853-873.

Spall, M. A., 1990: Circulation in the Canary basin: A model/data analysis. J. Geophys. Res., 95, 9611-9628.

— 1999: A simple model of the large-scale circulation of Mediterranean Water and Labrador Sea Water. Deep-Sea Res., 46, 181-204.

— , P. L. Richardson, and J. Price, 1993: Advection and eddy mixing in the Mediterranean salt tongue. J. Mar. Res., 51, 797-818.

Sparrow, M., O. Boebel, V. Zervakis, W. Zenk, A. CantosFiguerola, and W. J. Gould, 2002: Two circulation regimes of the Mediterranean outflow revealed by Lagrangian measurements. J. Phys. Oceanogr., 32, 1322-1330.

Stanev, E. V., 1992: Numerical experiment on the spreading of Mediterranean Water in the North Atlantic. Deep-Sea Res., 39, 1747-1766

Stephens, J. C., and D. P. Marshall, 1999: Dynamics of the Mediterranean salinity tongue. J. Phys. Oceanogr., 29, 1425-1441.

Stommel, H., A. B. Arons, and A. J. Faller, 1958: Some examples of stationary planetary flow patterns in bounded basins. Tellus, 10, 179-187.

Talley, L. D., and M. S. McCartney, 1982: Distribution and circu- lation of Labrador Sea Water. J. Phys. Oceanogr., 12, 11891205.

Webb, D. J., 2000: Evidence for shallow jets in the South Equatorial Current region of the southwest Pacific. J. Phys. Oceanogr., 30, 706-720.

_ A. C. Coward, B. A. de Cuevas, and C. S. Gwilliam, 1997: A multiprocessor ocean general circulation model using message passing. J. Atmos. Oceanic Technol., 14, 175-183.

- B. A. de Cuevas, and C. S. Richmond, 1998: Improved advection schemes for ocean models. J. Atmos. Oceanic Technol., 15, 1171-1187.

Willebrand, J., and Coauthors, 2001: Circulation characteristics in three eddy-permitting models of the North Atlantic. Progress in Oceanography, Vol. 48, Pergamon, 123-162.

Wüst, G., 1935: The Stratosphere of the Atlantic Ocean. Amerind, 112 pp. (Translated in 1978 by W. J. Emery from Schichtung und Zirkulation des Atlantischen Ozeans, Die Stratosphäre, Wissenschaftliche Ergebnisse der Deutschen Atlantischen Expedition Auf-dem Forschungs- und Vermessungsschiff "Meteor", 1925-1927, Vol. 6, No. 1-2, 180 pp.)

- 1961: On the vertical circulation of the Mediterranean Sea. J. Geophys. Res., 66, 3261-3271.

Zenk, W., and T. J. Müller, 1988: Seven-year current meter record in the eastern North Atlantic. Deep-Sea Res., 35, 1259-1268.

_ , and L. Armi, 1990: The complex spreading pattern of Mediterranean Water off the Portuguese continental slope. DeepSea Res., 37, 1805-1823. 